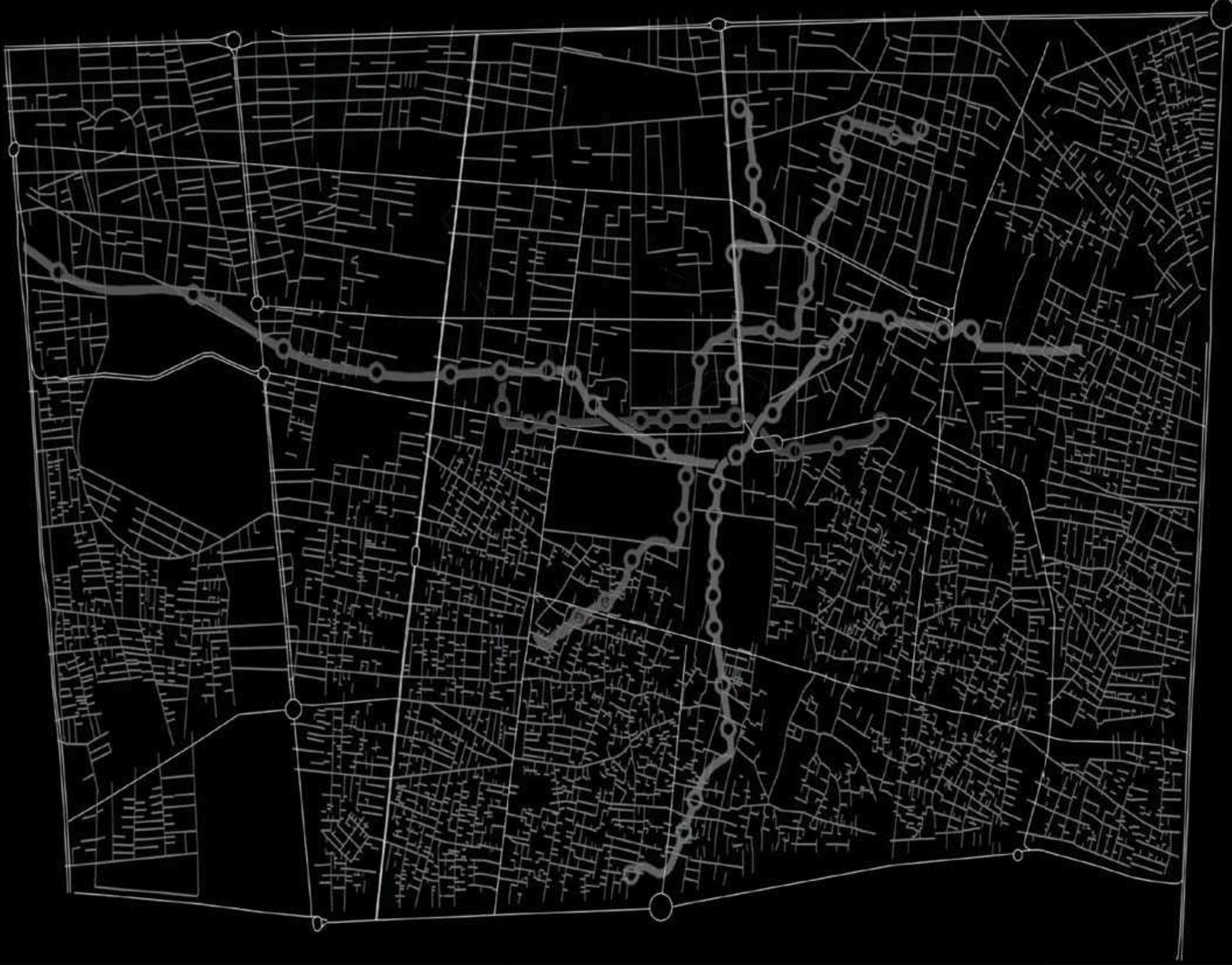


Mana Moradi-Haghgoo

A thesis submitted to the Faculty of Graduate and Postdoctoral Affairs in partial fulfillment of the requirements for the degree of

Masters of Architecture (Professional)

$$
\text { In }
$$

Azrieli School of Architecture \& Urbanism

Carleton University

Ottawa, Ontario

(C) 2018, Mana Moradi-Haghgoo
The aim of this thesis is to help provide safety in third world countries with the use of shelters. Due to the current global political climate of crisis, the need for shelter, or safety is a growing concern for a large number of people. Rather than focusing on the issue of sheltering those who are displaced during a time of crisis, this thesis looks at the critical need for shelter for people who stay behind in urban centers. This choice led to researching bomb shelters, which are temporary dwellings used in times of extreme duress. This thesis examines the possibility of channeling multiple existing underground subway systems in Tehran to create an alternative underground metropolis for times of crisis, which can help the individuals who choose to stay in the city during a time of crisis, due to complications, or necessity. Furthermore, this thesis provides a design that supports individvals through a crisis experience, when they are faced by emotional challenges. I investigate how architecture can provide a means to cope with emergency and crisis, through the strategic development of an underground shelter. In this context, some of the relevant design questions include: 
when underground? How does one cope with the lack of di-

rect contact with nature for prolonged periods of time?
I would first like to thank my thesis advisor, Professor Federica Goffi, who is the Associate Professor and Co-Chair of the Doctoral Architecture Program at Carleton University. The door to Professor Goffi's office was open whenever I ran into trouble or had a question about my research, or writing. She consistently encouraged me and allowed this paper to be my own work while also steering me in the right direction.

I would also like to thank the experts involved in the validation survey for this research project. Without their passionate participation and input the validation survey could not have been successfully conducted.

Finally, I must express my very profound gratitude to my parents, sister, brother and to my three best friends (A.B.R). They provided me with unfailing support and continuous encouragement throughout my years of study and through the process of researching and writing this thesis. This accomplishment would not have been possible without them.

Thank you All.

Mana Moradi-Haghgoo 
Table of Contents

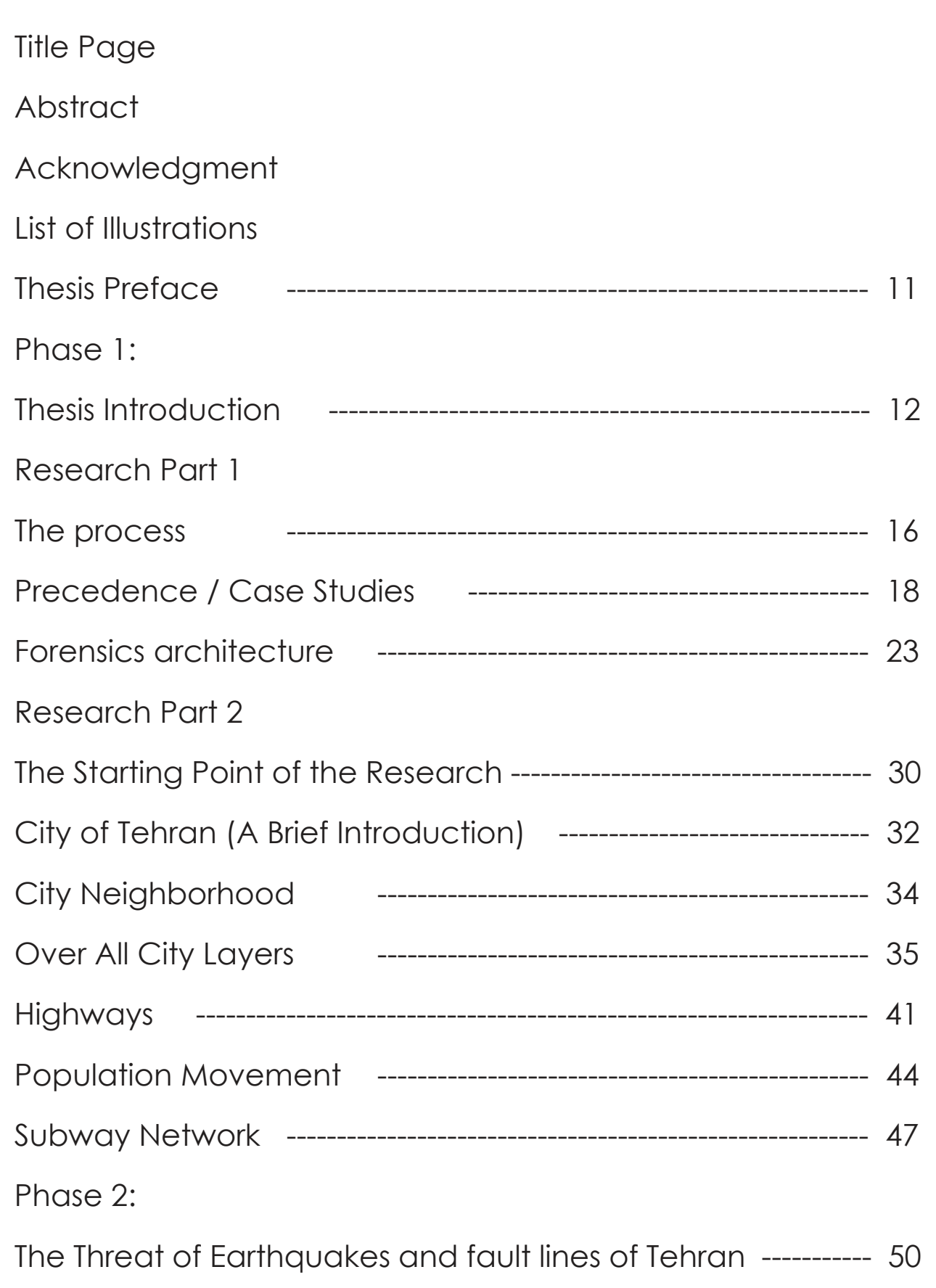

The Disconnection

Subway Design

Risk Assessment - - 55

Construction Method 58

Site Selection 60

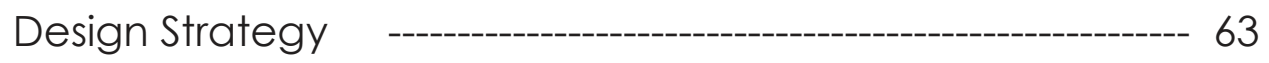

The Remote Skylight

Plans

Sections 75

Axonometric --- 77

Comprehensive Section

Emergency Exits - 80

The Underground Experience - - 82

Conclusion 91

Annotated Bibliography 92 
The Big Scope View

The Underground City of Dixia Cheng -

The Underground City of Naours

The Deep Level Shelter Tunnels

The Deep Level Shelter Tunnels

The Diefenbunker

Allepo's Demographic Map

Strike Locations

M2 Hospital Forensics Architecture

Al-Jinah Mosque Forensics Architecture

Design Proposal

Overall City Layers

District 12 Selected

Major High-rises in Tehran

Fault Movement

Population Movement -..

Subway Lines In City of Tehran

Major Fault Lines in Iran

Twin tube tunnel with single track

Mono-tube tunnel with two tracks

Mono-tube with two tracks and central dividing wall ----
Site Selection

The Vision of District 12

Hidden Emergency Exits

Subway Entrance

The Idea in Mind - - 66

Finalized Design Plans

The Remote Skylight $\quad$ _

Subway Level -

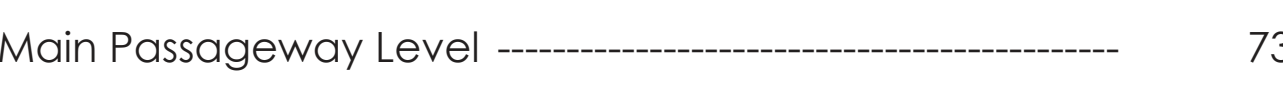

Secondary Programs (Multi Functional)

Section A

Section B - --- 76

Axonometric View

Comprehensive Section ---

Emergency Exits -

Renderings 
Thesis Preface

My motivation to pursue this thesis topic comes from my background, having witnessed the people of Tehran, the capital of Iran, suffer because of political matters, I have developed an interest in the question of providing temporary dwellings for people in difficult times. 
Phase 1:

Thesis Introduction

When countries become politically unstable, the need for economic and territorial security increases. More specifically, the need for moving people from a hazardous situation to a temporary dwelling becomes a highly contentious issue, especially in times of crisis. A temporary dwelling is a crucial step in the recovery process and in the process of reconstructing homes and lives in the aftermath of a disaster. These temporary structures are brought to life when a disaster strikes. The reconstruction and rehabilitation phase begins with temporary dwellings, which can last until the crises is dealt with. It is also known that due to the nature of contemporary conflicts, it is increasingly more difficult to determine when a condition can be defined as one of post-disaster.

The following proposal could have a successful outcome for citizens since the approach involves pre-disaster construction in order to prepare for the possibility and the outcome of disaster events. In the pre-disaster phase, plans, revisions, designs, and disaster management programs will be used as critical resources to make it possible for these temporary dwellings to be brought to life, whether using new materials and building new structures, or using existing structures and the ruins in the city to expand on them.'

There are many forms of emergency dwellings. The most common ones have been used in post-disaster conditions, in times of war, or after natural events/catastrophes. These are known as temporary shelters, or temporary housing. Temporary shelters can also be public shelters, such as when one takes refuge at a friend's house, in a basement, at a community center, or inside other existing structures that can safely house several people during a crisis. These shelters are meant to house residents for a brief period of time and are not meant to permanently serve this purpose. Temporary houses, on the other hand, are prefabricated structures. Temporary houses will allow users to find shelter there and return to their normal daily activities. They are meant to facilitate shelter for longer periods of time, unlike temporary shelters. This option plays a role when users' permanent houses have been destroyed. Temporary dwellings are known to house people, or communities, which have experienced a disaster and

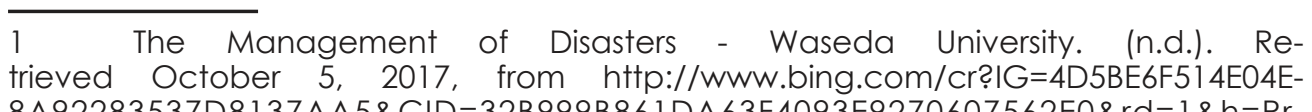

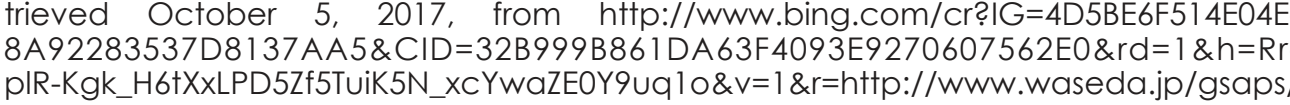

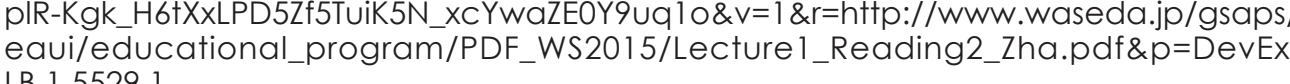


are trying to survive. These structures can either be above, or below grade, based on the circumstance. In this thesis proposal, temporary dwellings are discussed as extensions of the underground channels that already exist in the city of Tehran, as underground subway systems. The design proposal entails that they will be transformed into a dual use underground dream metropolis, where everyday functions can be easily converted in a time of crisis to offer temporary shelter. These dwellings can be combined with other communal services to serve the disaster affected community. Cities with a more stable political condition are better suited for this design proposal. Tehran was chosen as the site for the conceptual exploration of this fictional reality.

Throughout the history of Iran, many underground cities have come to life due to environmental reasons such as harsh weather conditions, or because of the need of residents to seek safety from enemy attacks and invaders. Many of these underground cities are now forgotten because they are no longer needed for protection and do not serve a purpose. Today, underground spaces form only
What is currently used as an underground space in the city includes spaces for communication and transportation within the city such as tunnels, transportation lines, and metro stations. These unused underground spaces can be re-purposed for a variety of applications. They hold potential for solving problems that take place on the ground level of the city.

For example, the proper use of underground spaces holds several the benefits. These could potentially include smoother traffic, decreased environmental pollution, and a reduced density in above ground spaces. Underground spaces could also be used for recreational purposes (sports facilities, parks, etc.), Commercial and office use (bazaars, etc.), Cultural purposes (libraries, museums, cultural centers, Cinemas, etc.) and other services (health clinics, hospitals, etc.) and parking lots for all of the mentioned programs. This issue is of paramount importance considering how Tehran faces numerous problems including traffic congestion increased air pollution, and the lack of green and recreationa spaces, which make the capital of Iran an urban environment that is in need of attention. 
The underground city of Dixia Cheng in China is an example of an underground shelter with channels and funnels spreading throughout the city. In 1968, tension escalated between the Soviet Union and China, which then lead residents of Beijing to start digging tunnels for their own safety. Their purpose was to serve as shelters during invasions, air raids, or nuclear attacks. These funnels were developed and dug out by hand. This was done by local men, women, and children. There were secret entrances to the underground corridors. Each tunnel was hidden in the back door area of homes, or businesses and in parks in order to render them invisible to the naked (Soviet) eye. These tunnels were dug about 8-18 meters underground, and extended the length of $30 \mathrm{~km}$, with a total area of 85 square kilometers. This sized area could accommodate 300,000 people for about four months. These massive spaces include approximately one thousand anti-air raid structures. They also included ventilation shafts, and waterproof gas hatches for protecting residents from radioactive fallouts. The tunnels were called "China's Underground Great Wall" because of their vastness and military purpose. They contained amenities such as barber shops, restaurants, playgrounds. more importantly, sites for growing sunless crops like mushrooms. However, these tunnels never served any purpose. When Beijing was no longer under threat, the underground city lost its meaning and purpose. Their existence slowly faded away and they were turned into a tourist destination. ${ }^{3}$

The second case study was the underground city of Naours in France. The Underground City of Naours is another great example of underground sheltering. This underground city, dug into chalks, consists of a large network of caves, rooms, and streets. The purpose was to hide people from Barbarians planning to invade their city. These caves spreads over three kilometers underground and can house around 3,000 people plus their supplies. They consist of bays with varied sizes to house different sizes of families and their animals. This structure has an abattoir as well as a large church. ${ }^{4}$

Similarly, the Deep Level Shelter Tunnels in London, England, are another underground sheltering example. The story behind them has to do with increased congestion on the Northern Line in the '30s. In response to this, a plan was developed to build a second 3 Dixia Cheng - Beijiing's Underground City. (2013, November 01). Retrieved
September, 26, 2017, from hitps://www.atlasobscura.com/places/dixia-cheng-beijing-s-sunderground-city

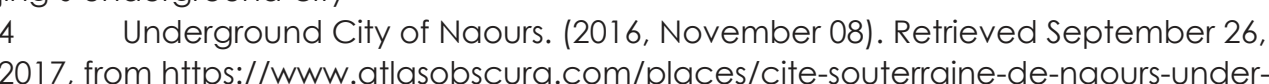
2017 , from
ground-city-of-naours

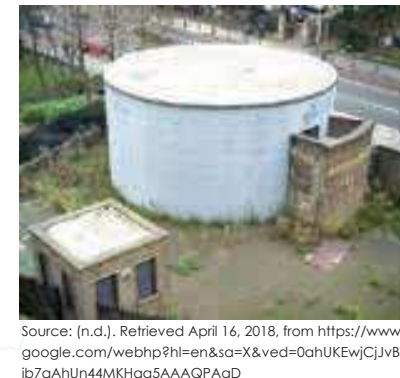


pair of funnels parallel with the Charing Cross branch of the Northern Line, which would act as an express route through London. These plans were shelved at the outset of the Second World War. Yet, as the Underground platforms became increasingly used by the public overnight as air raid shelters (despite being initially discouraged), work began in 1940 on building deep level shelters, which were envisaged to eventually become the platform tunnels for the express route. Above ground, each shelter's shafts were protected by purposefully constructed 'pill box' buildings to prevent bombs that directly hit the location from penetrating underground.

Each pill box housed lift machinery and provided the cover for spiral staircases that descended down to the shelter's tunnels. Each shelter was originally designed to house up to 12,000 people, but by the time they were built, the number of bunks had been dropped to a more comfortable 8,000. Bunks were arranged along the walls in various configurations to maximize the use of space. It was hoped that when their wartime use had come to an end, tunneling would re-start to allow the already constructed tunnel sections to be interconnected, solidifying the express Northern Line and have interconnecting tunnels that links them together. In some cases, these interconnections have since been blocked. Most of the shelters took about a year and a half to complete. Yet, amazingly, the government had cold feet about using them as public shelters since they were incredibly expensive to maintain.

After the Second World War came to an end, plans to create the express route were delayed, and then ultimately dropped because the money for the project was not available. Most of the shelters found use after the war, initially as accommodation for the army in transit, and most are today in use as storage facilities. Since they are now being used for other purposes, all the deep level shelters have been isolated from their associated active underground stations; in most cases, the interconnected tunnels ended up being bricked up. ${ }^{5}$

The Diefenbunker is a fallout shelter located in Ottawa. It was

commissioned by Prime Minister John Diefenbaker in 1959 as part

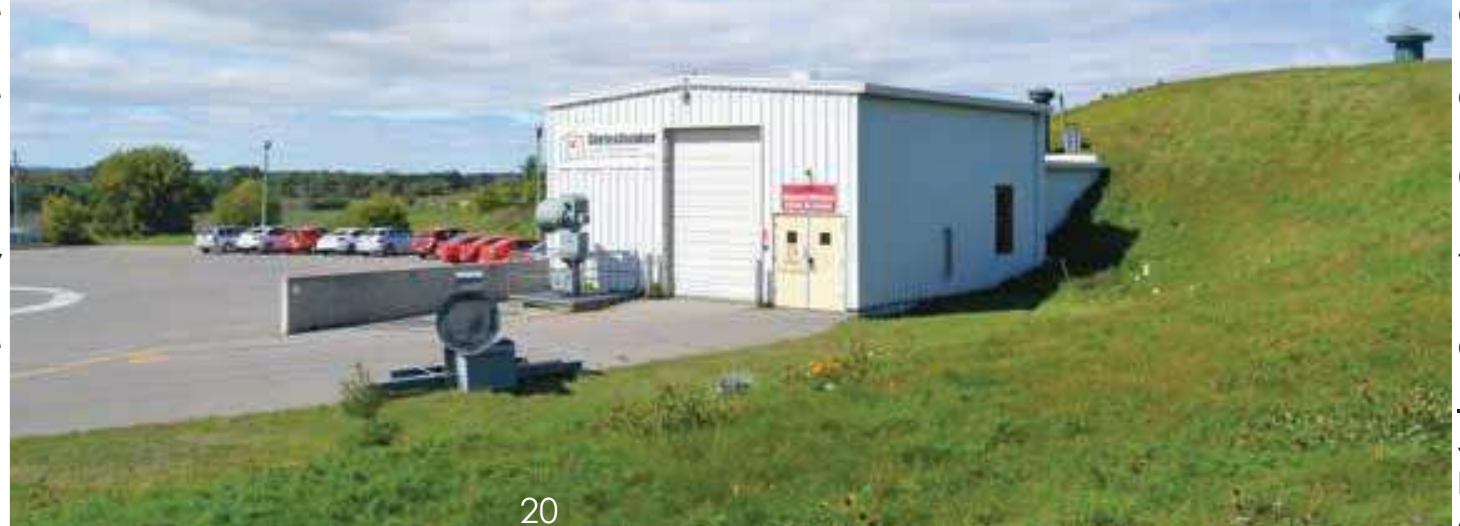
of his government's reaction to escalating tensions during the Cold War period (1940s-1970s). The purpose of the bunker was o house key members of the government and militaries in the event of a nuclear attack on Canada. 
It was designed and engineered by the Foundation Company of Canada, and the project was led by LCol Ed Churchill. The entire construction process took less than 18 months and was the first recorded use of a critical path construction methodology in Canada. The bunker has an area of 100,000 square feet spread over four levels. It is constructed out of 32,000 cubic yards of handpoured concrete and 5,000 tons of steel. It is an extraordinary marvel of engineering, and it is built to withstand a 5 -megaton nuclear blast from 1.8 kilometers away. ${ }^{6}$

\section{Forensics Architecture}

During my research process, l looked into the studies of Forensics Architecture in order to gain better knowledge on attacks and the related issues of structural integrity of buildings. This research is of importance given the nature of forensic architecture, which is described by Ewa Weinzman as:

"... An investigative practice that takes place after an attack, or a war event (...) It refers to the production of architectural evidence and to its presentation in juridica and political forums. It regards the common elements of our built environment (...) buildings, details, cities, and landscapes, as well as their representations in media and as data (...) as entry points from which to interrogate contemporary processes and with which to make claims for the future."

A few projects were studied in order to gain a better understanding of how structures withstand attacks, and which parts of buildings can withstand air strikes without being destroyed. There are many different detonation techniques, and a variety of bombs 


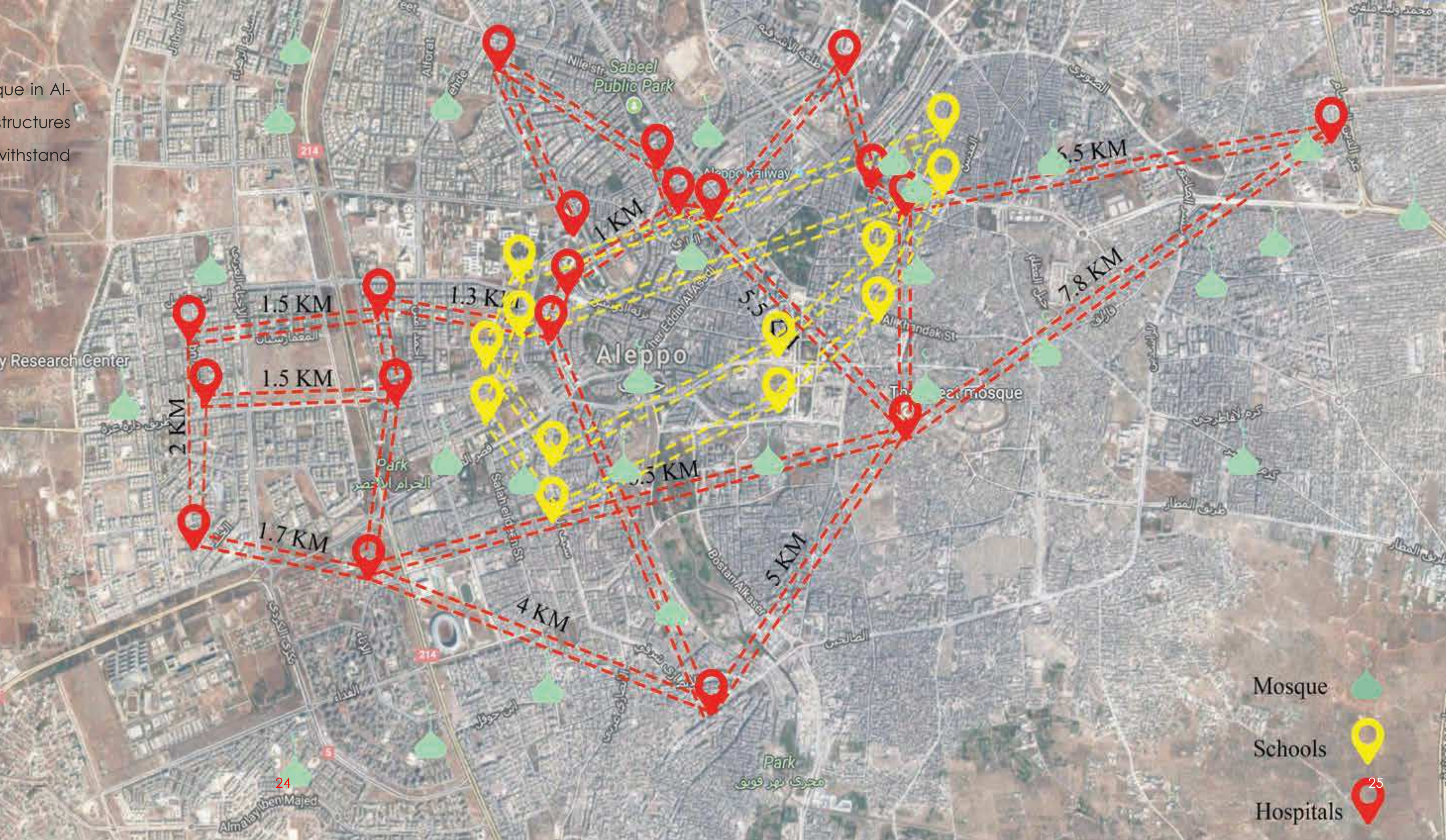


On March 16th 2017, a US drone strike targeted the Sayidina Omar Ibn Al-Khattab Mosque in Al-Jinah, in the province of Aleppo, Syria. When the strike happened, nearly 300 people were still in the building. Approximately 50 more civilians remained in the winter prayer hall, which was a smaller area where religious seminars occurred. ${ }^{8}$

After the attack, methods of forensics architecture were performed on the remains of the structure. The results showed that the surviving portions were staircases and the main entrance.
According to the Syrian American Medical Society (SAMS), the Omar Bin Abdul Aziz Hospital, also known as M2 Hospital, was subject to fourteen strikes by pro-government forces from June to December 2016. The hospital sustained considerable damage over this six-month period, which rendered it out of service many times. According to the UN, the M2 Hospital was one of only three hospitals left in Aleppo by mid-August 2016 that was still offering intensive care and the only hospital left with a pediatric department. 9
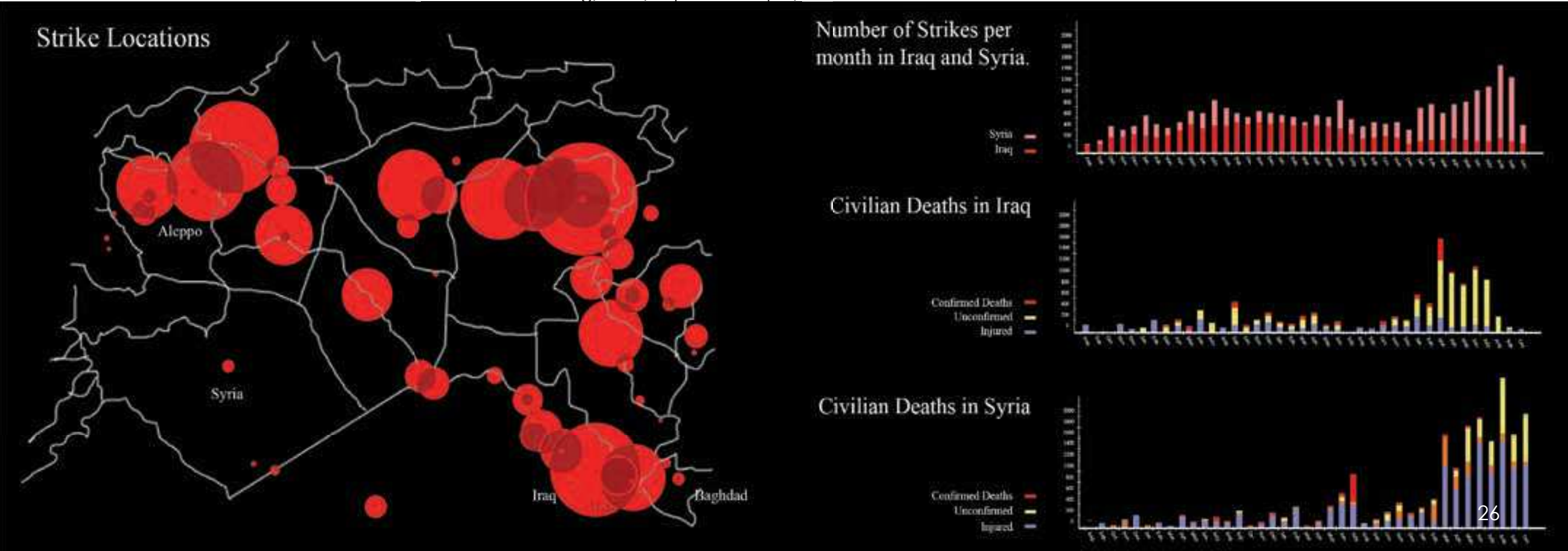


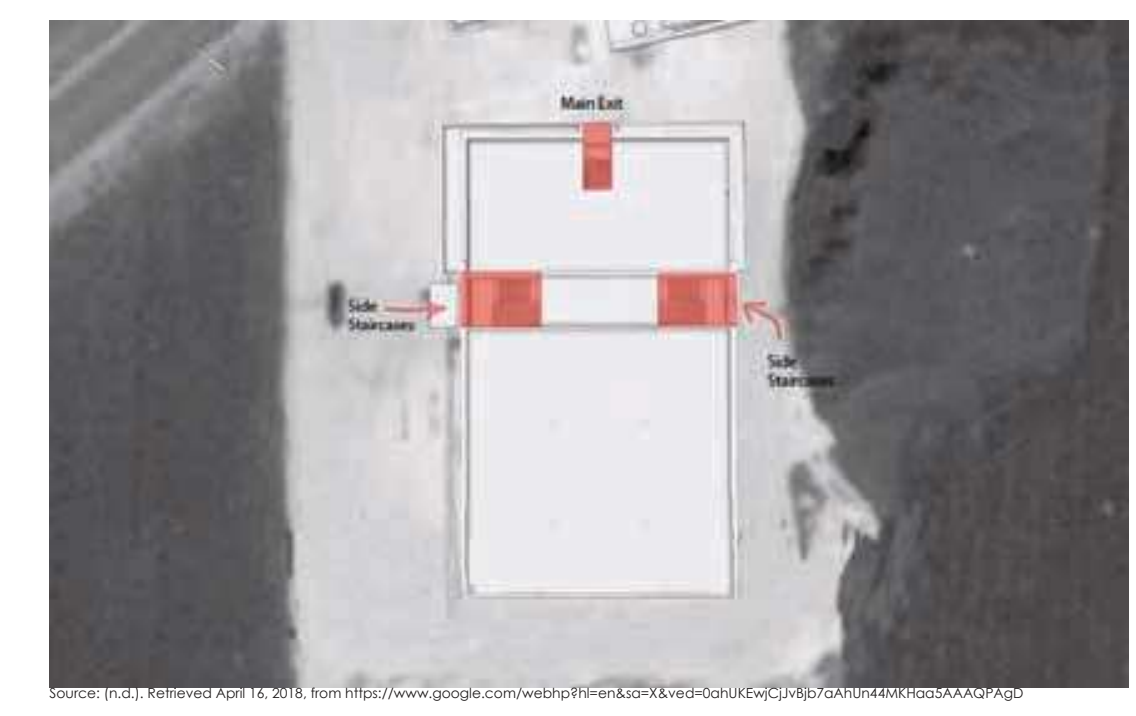

Like Al-Jinah mosque, after being investigated using forensics architecture techniques, the remains of the structure were identified as the main staircase and the main entrance. In both of these examples, the two strongest parts of the structure, the entrance and the staircase, withstood the attack, which made me realize that in my design, I could design these areas for emergency exit strategies in extreme situations. Since these type of structures have the strength to hold during an attack, it would be a wise idea to have staireases repeating throughout the design and connected with buildings on the ground for better protec tion. In this way people could evalevate buildings during an at tack and look for shelter underground. ${ }^{10}$

Furthermore, it Would be advisable that engineering consultants be asked to consider the design of new and purposely builtemer

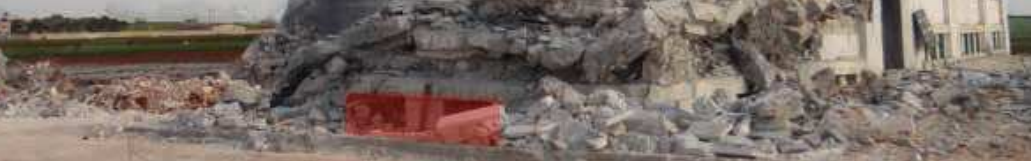

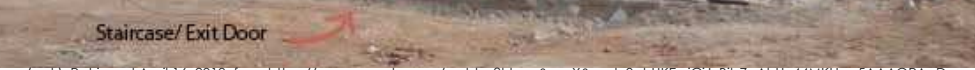

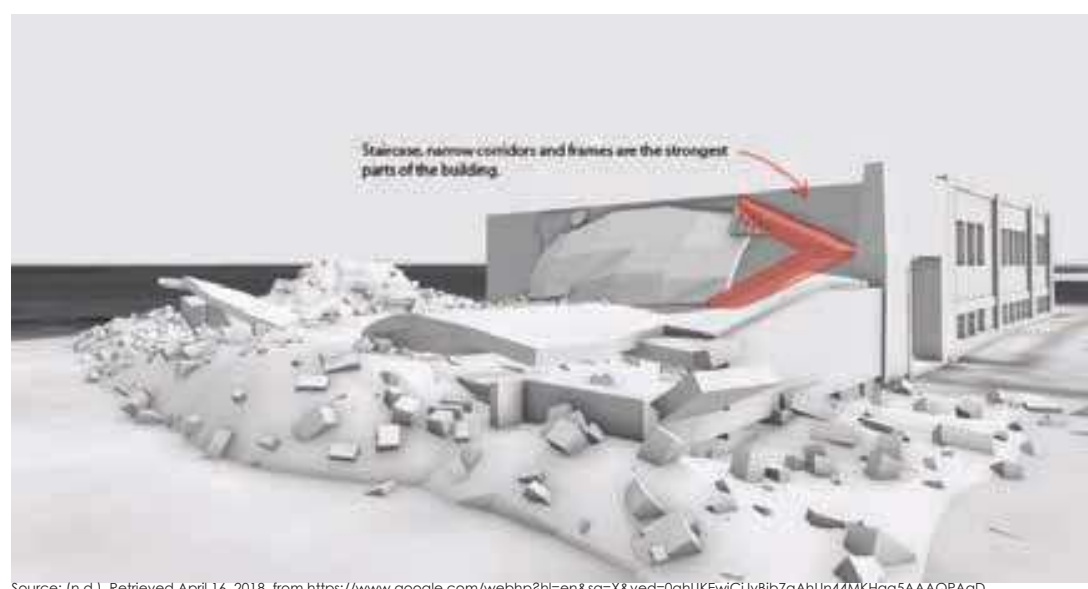
genoy-exits to withstand blasts and attacks.

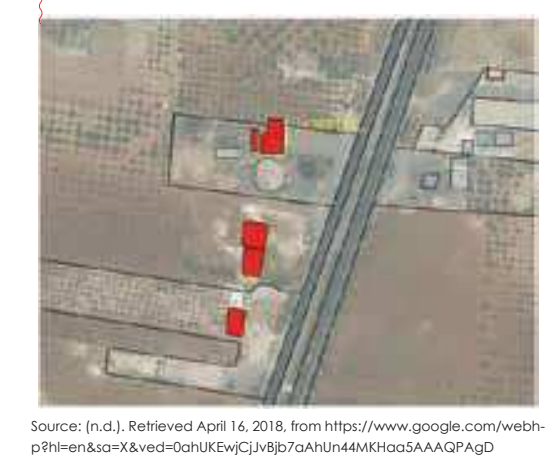


Research Part 2

The Starting Point of the Research

This thesis project is about adding connections to the existing un-

derground subway system, to design for a dual use. The subway system could be used as a temporary shelter, as well as an e eryday commute system for people. The focus of this research is mostly on the dual use of this system and how it can easily transformed from functioning as a shelter to facilitate daily task that people perform while commuting on a day to day basis Therefore, a detailed study of the city of Tehran's history of pop ulation movement, geological characteristics, significant buil ings, major public transportation flows, and city demograph needed to be examined and kept in consideration througho the design proposal.

After gathering this information, decisions could be made con cerning to which part of the city this fictional reality con could be applied to in order to help people in times of duress.
The suburbs of Telran come out of an extended
and open icty Hien hive residential has come to cat un most of the garcen
are disppearing rapidly
The Lower City: $1300>1100$ Downtown Tetran was abandoned for the Northeru

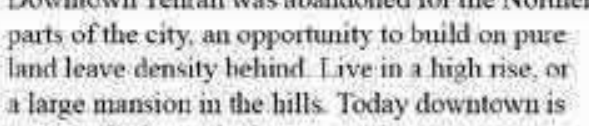

The Plain: 1100

90 million cube meters of polluted water
is pumped cut of the aricultural plaies

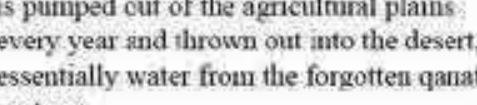
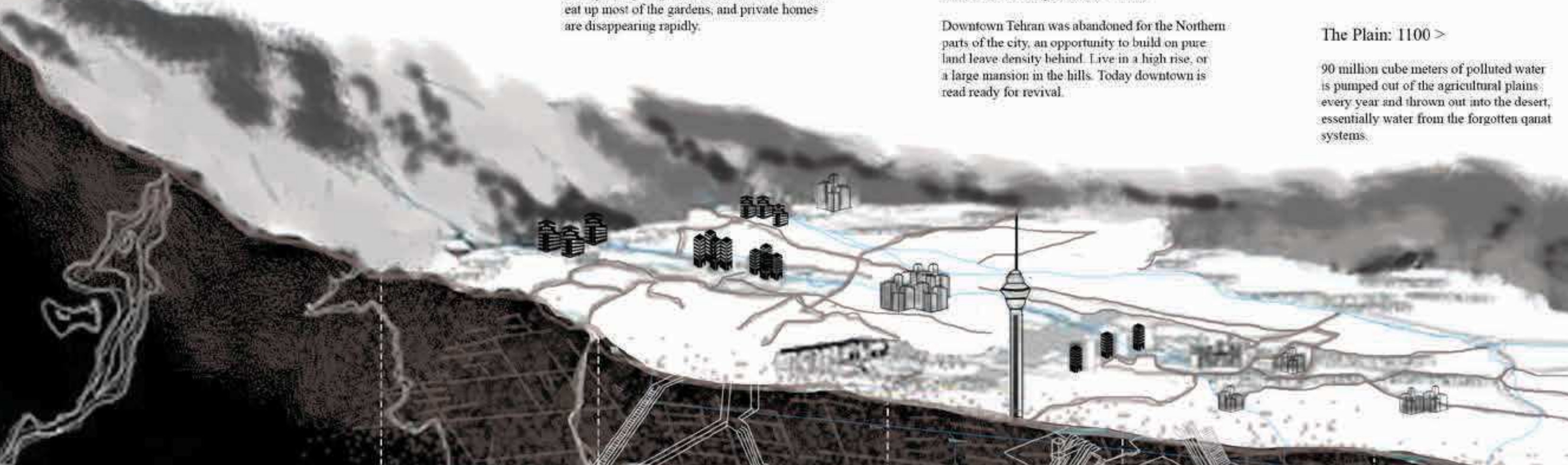
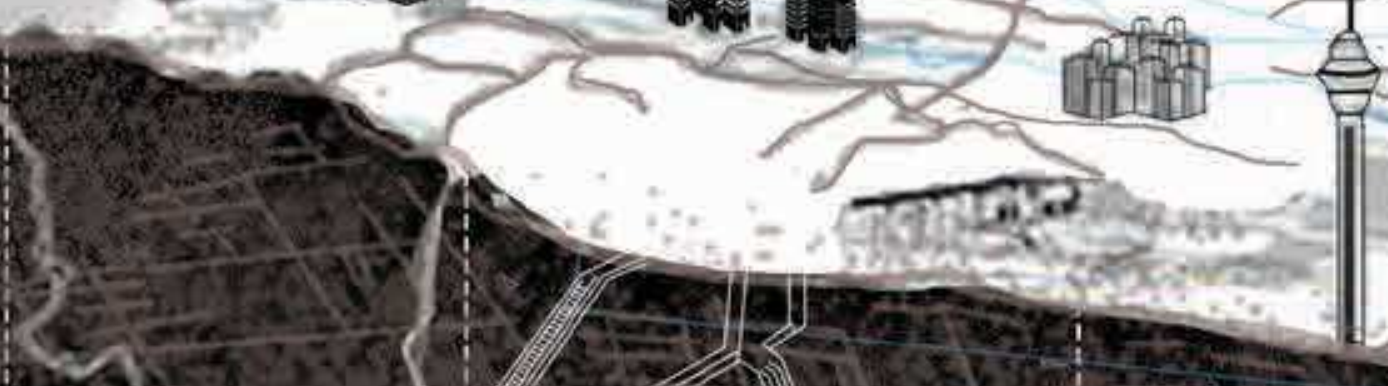

19. îi
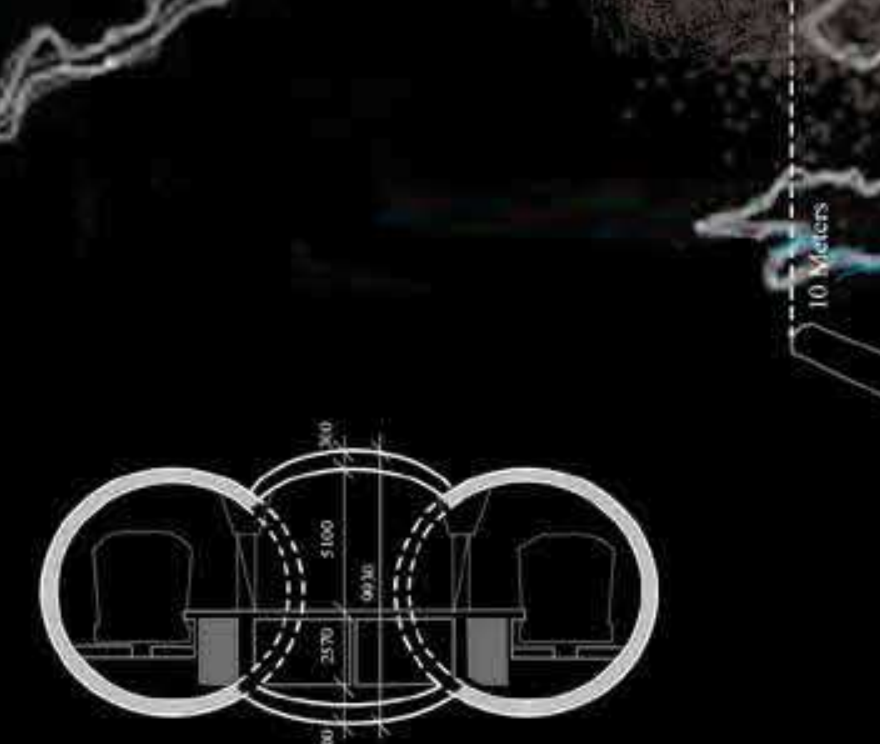

(.)

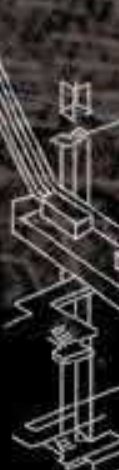

का 


\section{City of Tehran, A Brief Introduction}

Tehran is the capital of Iran and of the Tehran Province. With a population of approximately 8.8 million in the city and 15 million in its larger metropolitan area, Tehran is the most populous city in both Iran and Western Asia. It is the 25th most populous city and the 27th largest city in the world. It has the second largest metropolitan area in the Middle East and covers an area of 730 square kilometers. It is ranked 29th in the world for the population of its metropolitan area. The administrative structure of Iran is concentrated in Tehran, which is divided into 22 districts, (including Rey and Tajish)."

It is located in the southern part of the Alborz mountain range which is located at a distance of $112 \mathrm{~km}$ south of the Caspian Sea. The city has a dense highway network, seven active subway lines, and four lines under construction, which in the spring of 2011 (1389 in the Persian calendar), have displaced 129 million passengers. The height of the city reaches about 2000 meters in the highest parts of the north and 1050 meters in the southernmost parts near the sea. Tehran is facing the mountains from the north side,

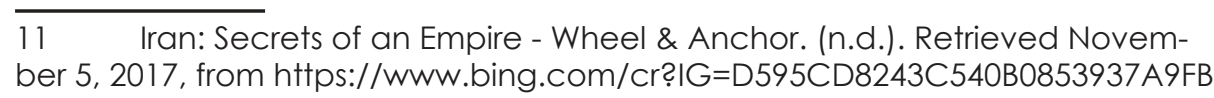

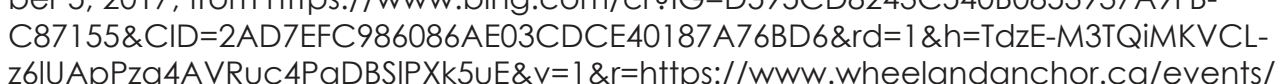
secrets-of-an-empire-tehran-to-shiraz/\&p=DevEx/B.1.5069.1 and from the south,

it faces the desert.

This results in different

weather conditions in

the south, where it is

dry and humid, while

a colder weather can

be found in the north

portions of the city.
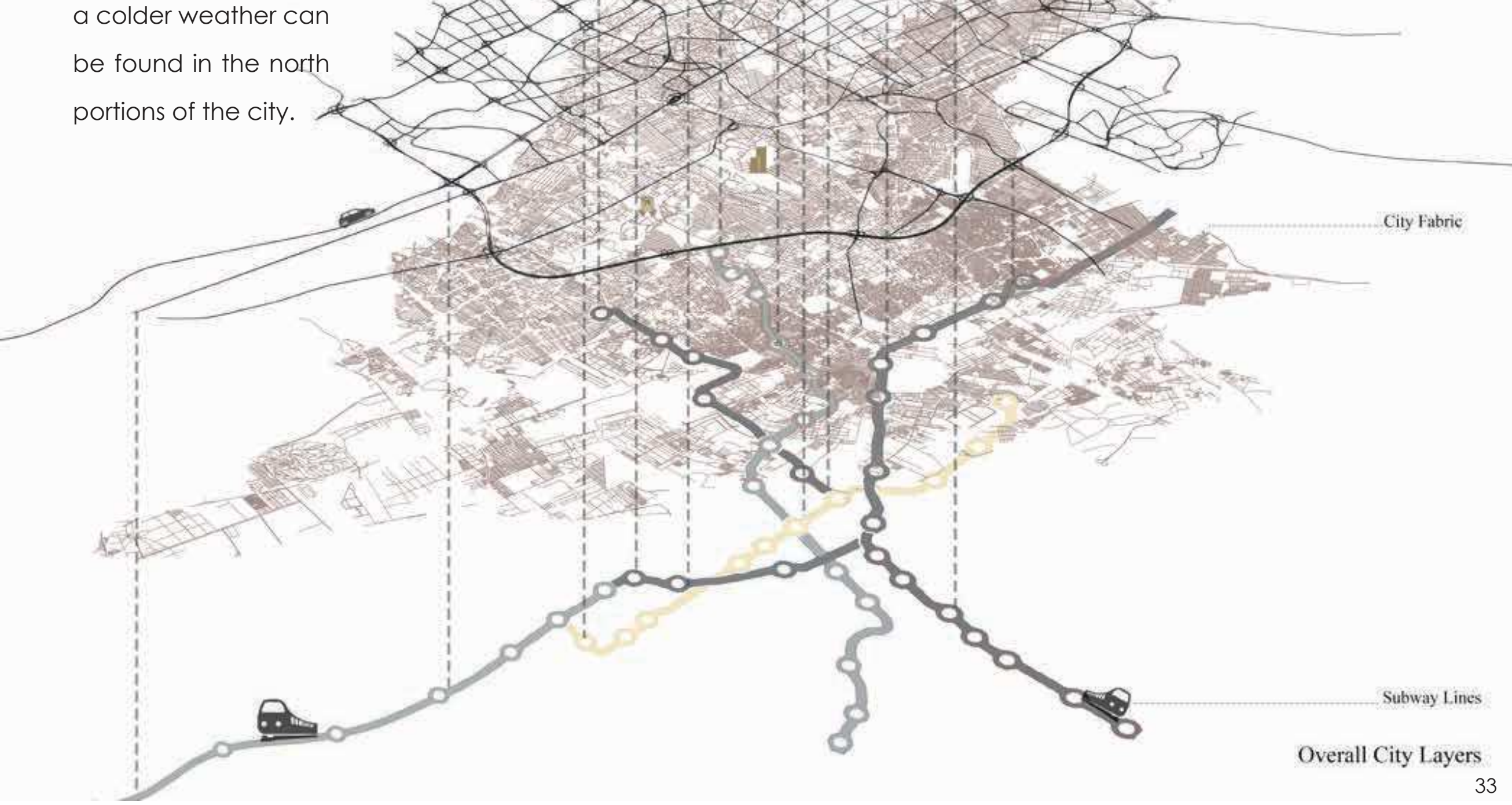


\section{City Neighborhoods}

The metropolis of Tehran has many neighborhoods and towns. The old Tehran consists of four neighborhoods called Sanglan, Oudlajān (Oudlajān), the market, and the hole. In the time of Naseral-Din Shah Qajar, several new neighborhoods were constructed such as Arg, Haleh Hesar, Khaniabad, Qnatabad, Pachnar, Pamenar, Ghar Mashhad, Gud Shabbarkhani, Soap Factory, Gud Arabs, and Qazvin Gate. Valiasr Street is the longest street in Iran, as well as the longest street in the Middle East. It was built in the early years of Reza Shah's Kingdom. Its length is $18.6 \mathrm{~km}$, starting from Tehran Railroad Field and ending at Tajish Square in Shemiranat Region. ${ }^{12}$

\section{Demographics ${ }^{13}$}

In 1164, prior to the establishment of the Qajar Dynasty and its nomination as the capital of Iran, Tehran was just a small town with a population of 15,000 . Since then, its population has grown. It became the largest city in Iran in the middle of the Qajar period. According to the census of 1264, Tehran's population counted 147, 206 people. According to the first official census

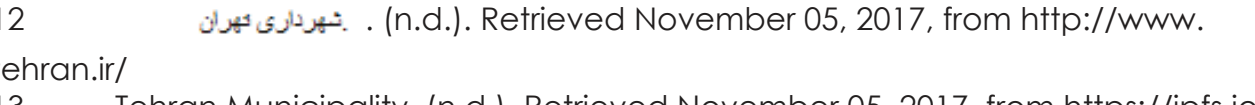

conducted in 1956 (1335 in the Persian calendar), the city had 1. 560, 934 people and was the most populous in Iran. The population of Tehran according to the census 2016 (1395 in the Persian calendar) was 8,693,706.

\section{City Layers ${ }^{14}$}

With the aim of understanding the site condition, I examined the city on a large scale. I sought to understand the city structure and its people. Tehran has several major city layers: major highways, major transportation pathways, the infrastructure, the urban layer and underground subway tunnels.

\section{The Old Texture}

The old Tehran region has the most valuable buildings in the city and is considered to hold the historic identity of the city. On the other hand, historic Tehran (Tahmasbi) is the main core of Tehran. The old Tehran region is close to Tehran's Nasseri, and many of the important buildings of the first Pahlavi period are located in this area. Some of its areas, such as the National Garden, have been well protected. Here, there are connecting streets that currently 


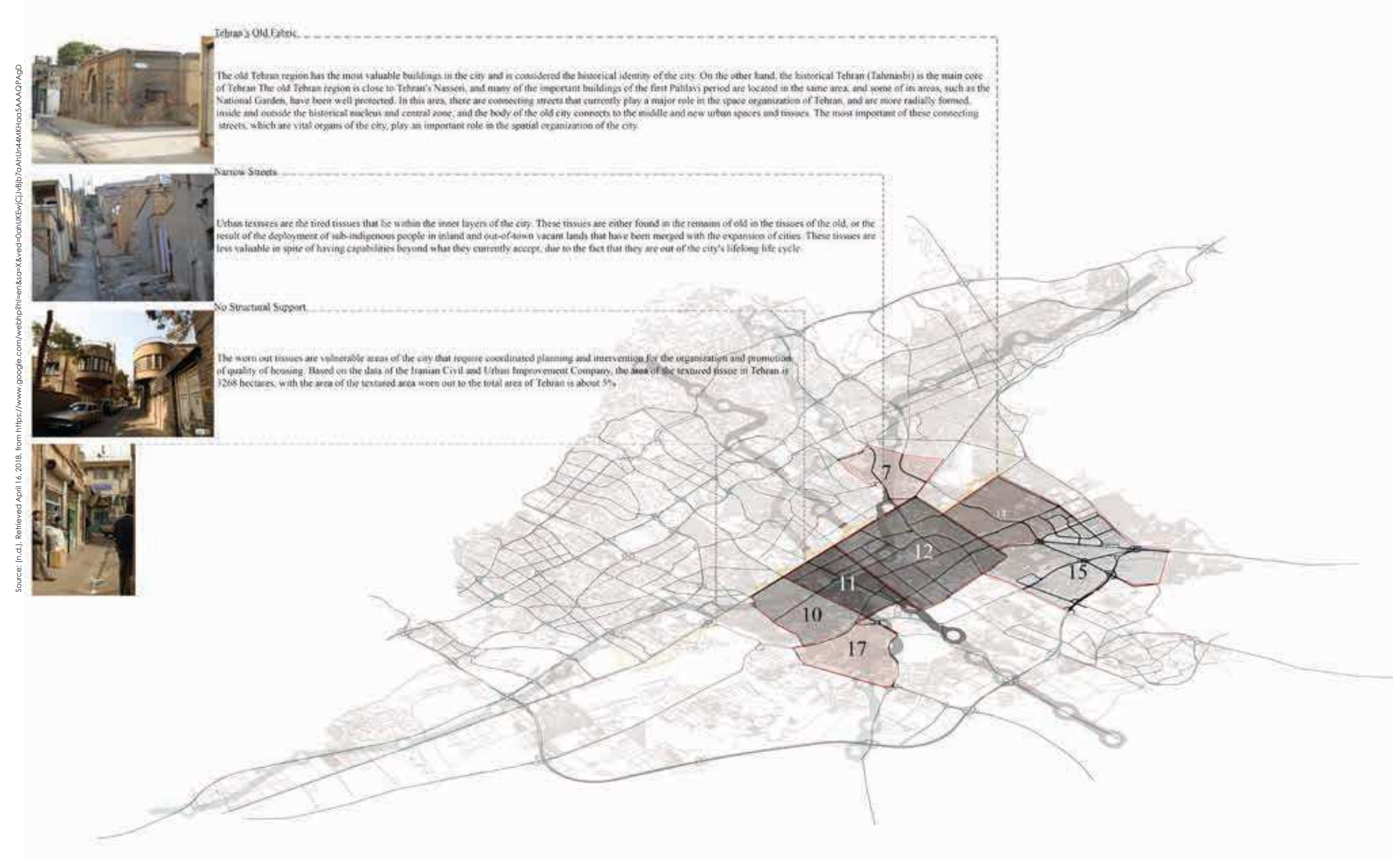

play a significant role in the spatial organization of Tehran, and are radially formed, inside and outside the historic nucleus and the central zone. The body of the old city connects to the middle and new urban spaces. The most important of these connecting streets, which are vital organs of the city, play a key role in the spatial organization of the city.

As the oldest existing layer in the city, the lack of structural support is evident in the buildings. These worn-out and vulnerable areas of the city require coordinated planning and intervention for the organization and promotion of quality housing. Based on data compiled by the Iranian Civil and Urban Improvement Company, this old and vulnerable are in Tehran consists of 3268 hectares, which makes up a total of $5 \%$ of the city. Aside from districts 10,11,12,14, 15 and 17, which contain most of the government institutions and high traffic, there are several important buildings in the city located in the north, which also have high traffic in terms of population use and movement.

These buildings are called: Tehran Newspaper Building, Ministry of Road Building, Central Bank of Tehran, Bonyad Mostazzafin Building, and Ati Saz Residential Complex. Aside from the governmen- 
buildings play a leading role in the city and in the flows pedestrian traffic. 15

So far, the focus of the underground design for additional pathway connections is on the central districts, since most government institutions and population movement is concentrated there. There could also be some additional branches designed in the northern part of the city where key buildings are located, but this will not be the focus of this thesis.

15 According to the book, The Destruction of Memory by Robert Bevan, in order to destroy a city within its core, the morality of the city needs to be destroyed. Usually
the morality of the city is hidden within the history of the city. The history of each city is usually hidden within its historic buildings and culture. Therefore, when the enemy residents, by destroying those buildings the morality of the city is also being destroyed. In this way, the memories people have from the buildings will be destroyed. Bevan Writes: "Structures and places with certain meanings are selected for oblivion with
deliberate intent such as a mosque or an art gallen- which is meant for showing the deliberate intent. Such as a mosque or an art gallery which is meant for showing the
enemy the presence of a community and the other is meant for a cache of historica memory or evidence." Why do we often feel more pain looking at the image of a destroyed bridge than the
image of massacred peoplea? This sis because we see our mortality in the collapse of the bridge but we offen expect people to die. The destruction of the bridge is like the destruction of a monument to civilization. The bridge is meant to outilive us. A dead

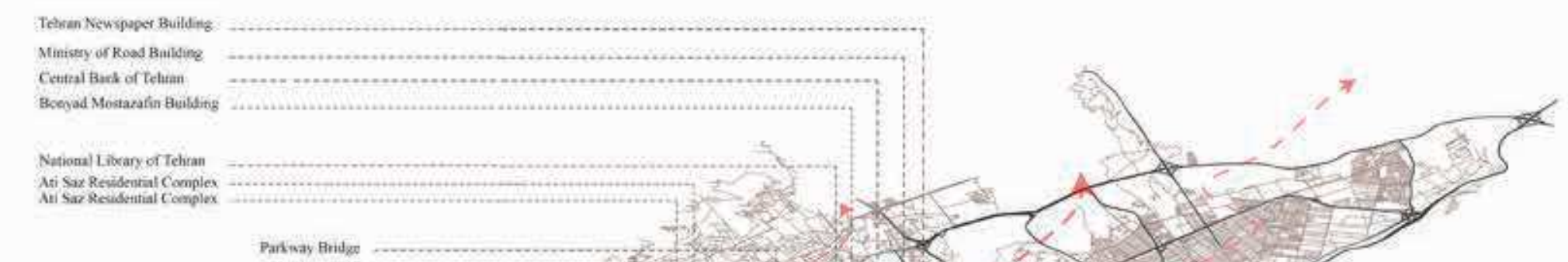

i
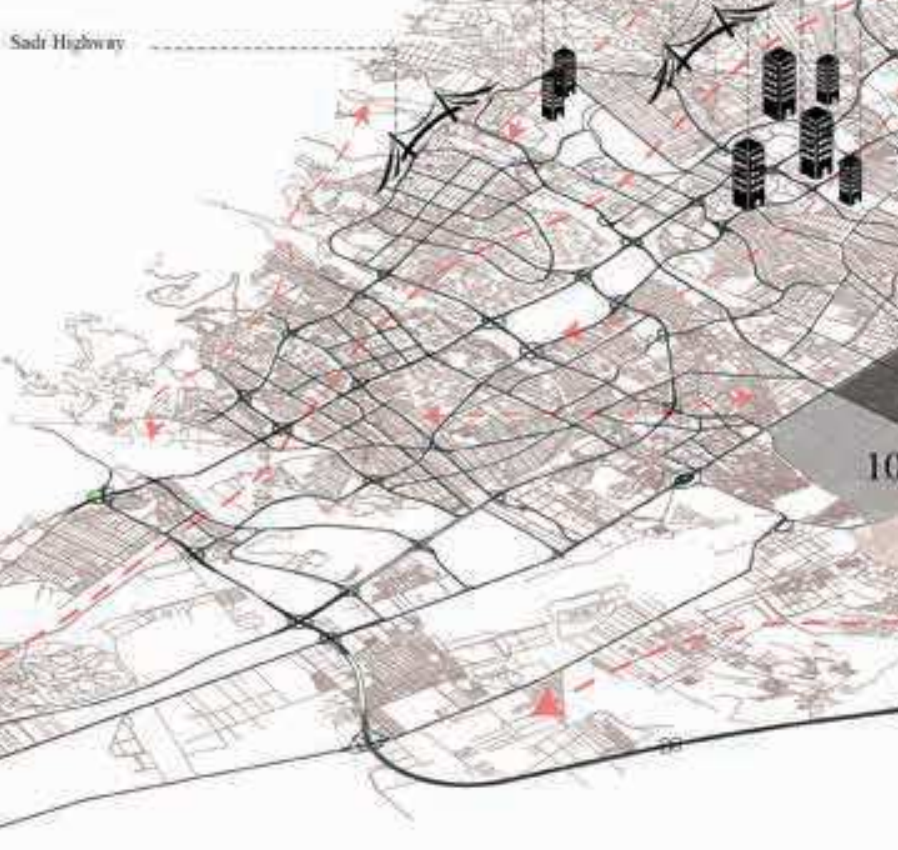
$=$

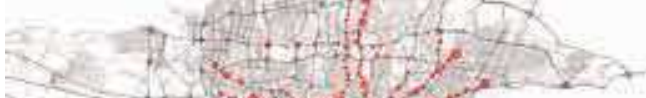


The context is the new development of the city of Tehran and the old historic core of the city, especially in the last half century. The growth of residential areas, public services, cultural services, recreational facilities, and sanitary textiles in this area will foster the development of new spaces in Tehran in the decades to come. In terms of physical appearance, this growth is remarkably different from the historic texture of Tehran, both in terms of landscape and pattern, and in terms of population groups. The regular and relatively wide networking pattern, the type of construction materials, the number of floors, and the pattern pre-programmed in this range, is obvious. Despite the development of the last few decades, the bulk of the city's service elements are still in this area, although its residential capacity has declined in favor of service and public functions.
Tehran has a widespread and complex network of roads and streets. Since the city has suffered from traffic jams for many years, the government has been forced to design and construct highways, especially after the Islamic Revolution, in order to solve the traffic problems. The large crowds of Tehran and the heavy traffic of cars led to the transformation of the streets into parking lots and the creation of countless traffic jams in the city, which resulted in a waste of time and increased economic pressure on the citizens. In addition, the increase in air pollution is also an issue. In the fall of 2007, the Tehran Comprehensive Transportation and Traffic Engineering Plan was approved. The plan's general objectives are based on the goals of other vast plans such as Tehran's Master Plan, as well as the fourth economic development plan of Iran. It outlines the prospects for the city's desirable development in the next 20 years.

\section{Urban divisions}

Due to political changes and population growth both during the Pahlavi dynasty and after the 1979 revolution, the city has experienced regional change. Many neighborhoods and settlements were initially built in Tehran's metropolitan area 
and in 1347, the first comprehensive plan of the city of Tehran was announced in which the area of the city was dramatically increased to 181 square kilometers and divided into 12 districts. After the victory of the Islamic Revolution, the number of Tehran's regions increased to 20. Subsequently, in the early 1970s, and after the reexamination of the Western city of Tehran, four new districts $(9,5,20$, and 21) were created and the total number of Tehran's districts increased to 22 .

When it comes to designing underground structures, several factors need to be taken into consideration. These include the type of soil, the geology of the ground, and possible fault lines that might result in earthquakes, which are factors that will be discussed further in future chapters.

Tehran is located on several fault lines. Most of them are in the northern part of Tehran. Therefore, there are major risks of possible casualties in times of crisis. The northern faults are called the Niavaran Fault, the Northern Fault, which is the longest, and the Reverse Fault. The South Fault and the East Fault are in the south and east regions of Tehran. Garmdaneh Fault is on the Northwest side and Mahmoodiyeh Fault stretches towards the center of

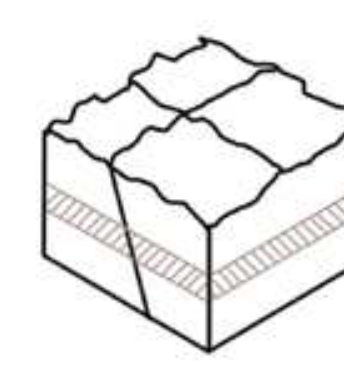

No Fault

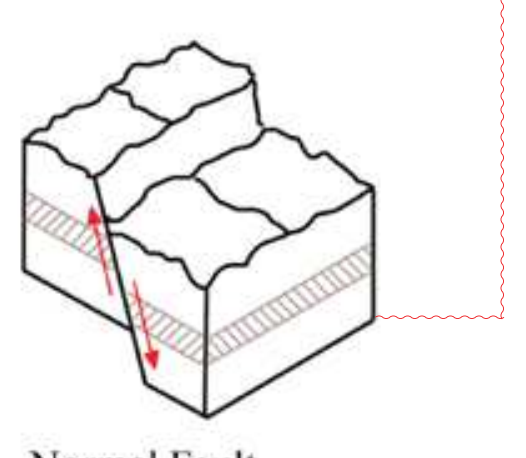

Normal Fault

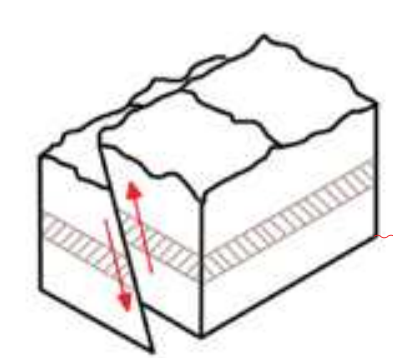

Reverse Fault

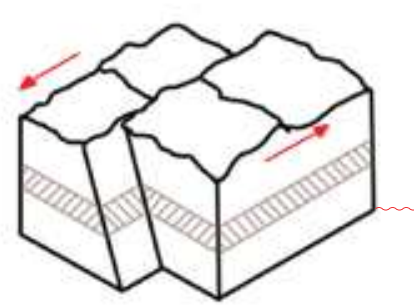

Left Lateral Fault the city. In the occurrence of an earthquake, the earth moves in several different directions. The first fault movement is called Normal Fault, which is when the earth splits and the direction of movement is, the second one is Reverse Fault which, and the last one is the left lateral fault. 
One of the central points of this research concerns understanding the movement of people. It aims to locate the most populous section of the city. I have gathered information on pedestrian movement and public transportation, since they are the focal points of the design. The following map shows the average movement pattern of pedestrians on foot and while using public transportation daily. In this representation, the larger the circle, the more population is present in the area. Since all the governmental and major economic businesses are located in the heart of the city, district 12, all major public transportation and movement are happening there.

Public transportation and pedestrian movement are at its peak in the central core. Thus, the major underground development should be in district 12, so that it could be put to maximum usage. since the central core of Tehran has an old fabric that results in narrow streets and no structural support, the risk of having casualties and for people to be in danger is higher there when a disaster occurs. Therefore, it would be critical for people to have alternate evacuation routes. The design proposal of the underground extensions would serve the community and provide for the needed safety.

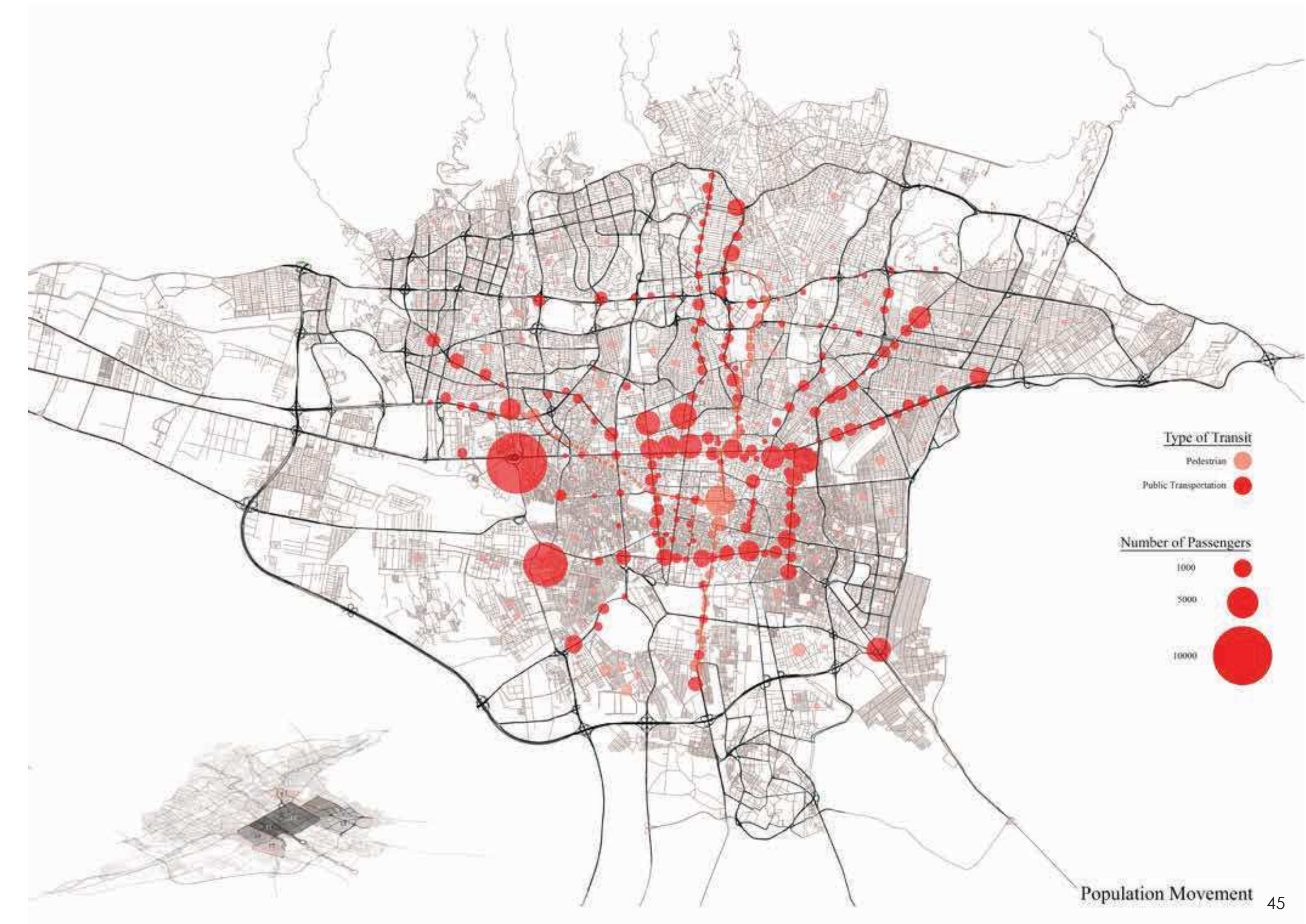


Tehran has a very busy public transportation system with high concentrations of pedestrian movement. Because of the high population in the city, traffic is always an issue and transportation from one point to another can become difficult. The population movement research is based on patterns of daily movement throughout the city. The pink circles represent pedestrian movement and red circles represent public transportation. As shown, most of the transportation and pedestrian movement is located in the central core of the city. The reason, as mentioned earlier, is that most of the governmental institutions and businesses are located in the center of the city, as it is the case with almost every city. Therefore, most of the jobs and opportunities for growth are in the heart of the city. This causes most of the traffic congestion and chaos within the central core of the city.

Since traffic is often congested and finding a parking spot is near impossible, most of the people take public transportation to get to work, or to commute within the heart of the city. Thus, these proposed extensions will be a good solution to the problem since they will help with traffic, and they are functional on a daily basis. The extensions can help people commute easily when the weather is not in their favor and they can also act as an emergency shelter if needed.

\section{Subway Network}

The history of the discussion concerning the construction of a city tram in Tehran dates back 110 years. The establishment of a city tram was one of the foremost points that Baron Julius de Reuter came up with at the time of Nasir al-Din Shah. Around the same time, a rectangular railroad was built between the city gate Rey (Hazrat Abdul Azim) and the Garden of the Shah, known as the famous Smoke Machine. Tehran's subway system is designed in nine lines, but currently there are only seven active lines: the first line, which runs from Tajish Station to the Kahrizak Subway Station, has the most passengers. The second line starts from the underground train station and continues to Sadeghia subway station The third line, from the Azadegan subway station to the Ghaem Metro Station, is also currently active. The fifth line extends to the metro station in Golshahr (Karaj). The fourth line travels from the Eram Green metro station to the Shahid Khodadoz metro station. In March 2015 (1394 on Persian Calendar), through the 


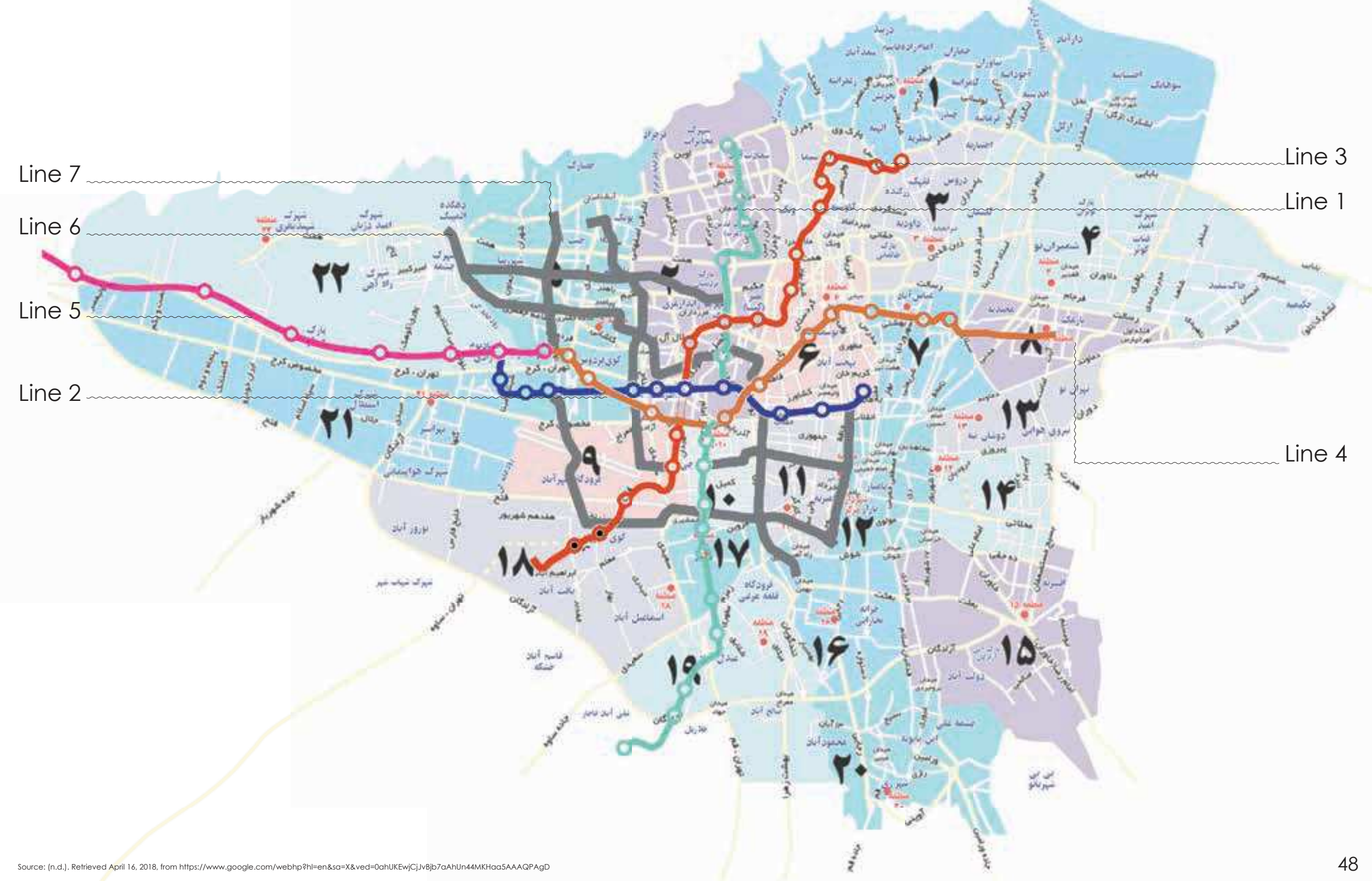

construction of a sub branch on line 4, Tehran's subway system was connected to These new extensions and passageways will be added to the lines that are currently under construction since the project is yet to be completed. The purpose of this fictional concept is that it can be easily added to different segments of underground subway lines."

Tehran has been destroyed by catastrophic earthquakes. As a result, the eval-
uation of the effects of earthquakes on the seismic design of buildings in Tehran is indeed very necessary. seismic cod is having a reasonable value for the design basis acceleration over bed rock (A) that satisfies the scientific principles. GHODRATI AMIRl, G. (2004). Evaluation of near-field earthquake effects. NEAR-FIELD EARTIHQUAKE EFFECTS ON IRANIAN DESICN 
Phase 2

Since Tehran is geologically positioned on active fault lines that cause earthquakes, it is important to locate these active faults around the city and prepare for the possibility of natural disasters to occur, which will affect tunnel safety and design. Among many active fault lines in Tehran, the probability of activation of the three faults is such that the "Masha fault, North Tehran fault, and south rii fault" are more likely to be activated. Due to the lack of attention to the strength and foundations of buildings, in the event of an earthquake in Tehran, there could be a considerable number of casualties and significant ruins. As illustrated in the earthquake map, there are no major fault lines in the central core of the city. This makes it clear that there needs to be no appropriate design for tunnel structure but merely a basic seismic

18 Because many important cities like Tehran, Shiraz, and many other cities are
located in near active faults, and the occurrence of large earthauakes are probable in Iran, occurrence of large earthauakes close to important cities in Iran is inevitable. so the importance of this research is obvious. Andisheh, K. \& Ghodrati Amiri, G. 20111 ). Evaluation of Iranian Code No. 2800 for Seis
mic Resistant Design of Nears ource Buidings Based on Real Record of rara. Evaluation of franian Code No 2800 for Seismic Resistant Design of Near Source Buildings Based on Real Record of Iran, 20(2). Retrieved from hittp:///scholarsmine.mst. edulicrageesesd//05i-

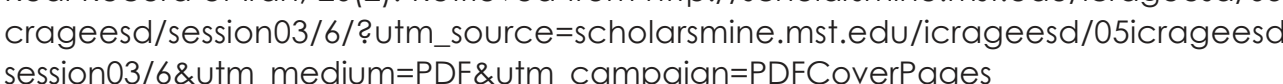

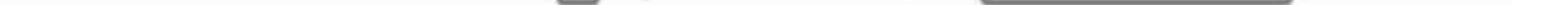




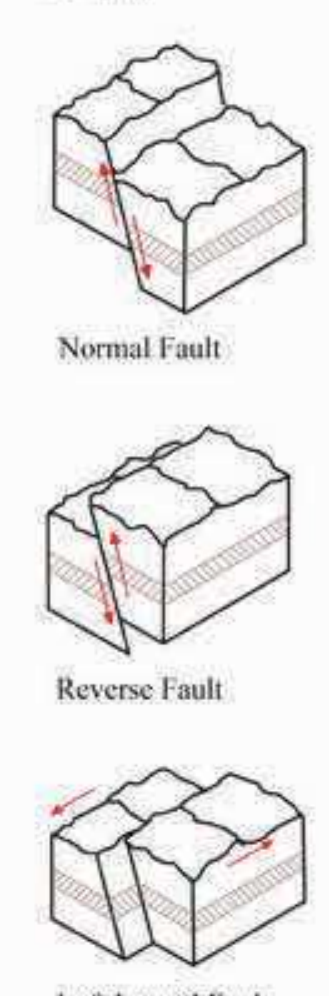

Ient tateral Fault

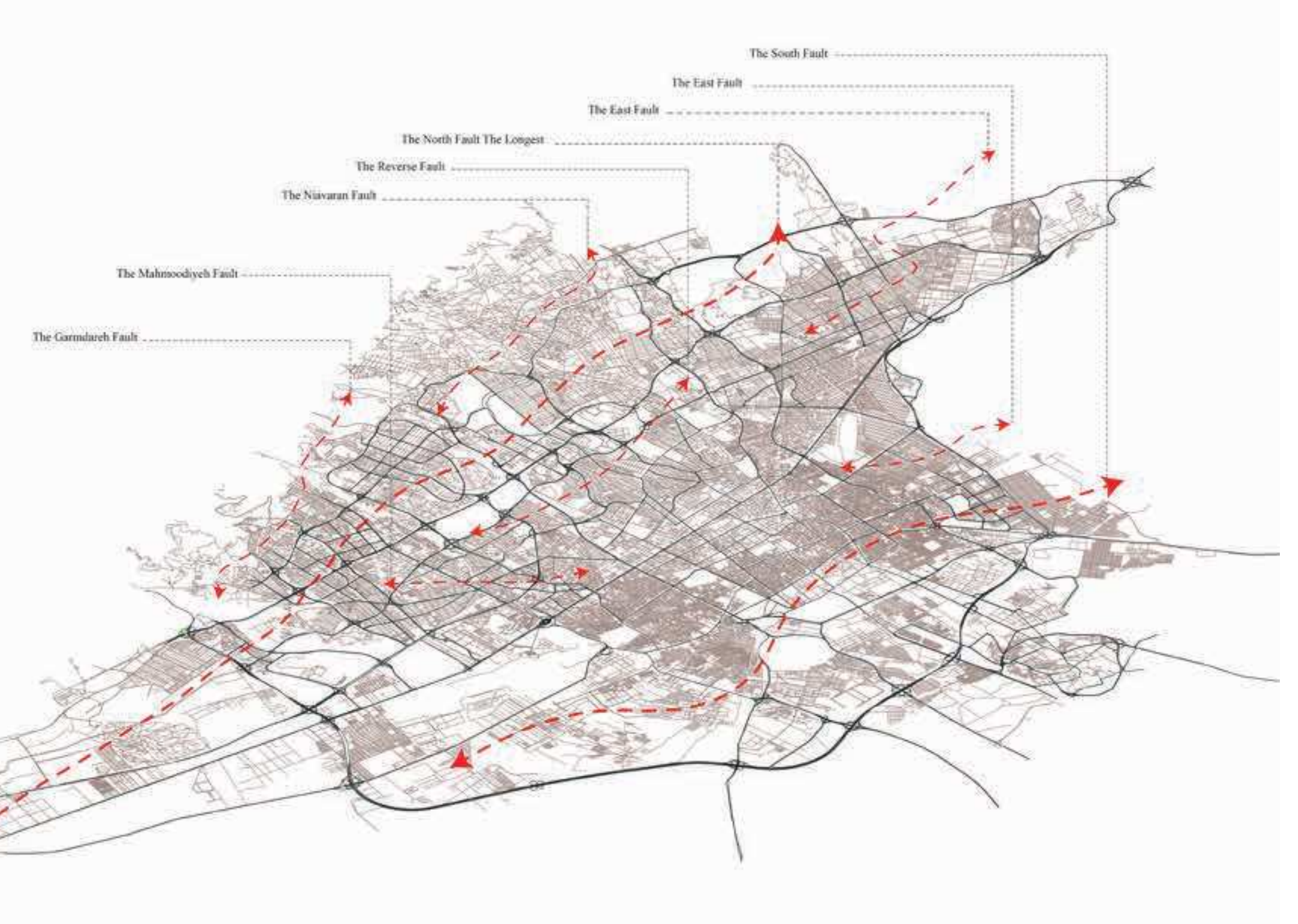

Tehran's Major Fault Lin design so that they can withstand any possible earthquake shocks. ${ }^{19}$

\section{The Disconnection}

After the mapping phase, and for a period of about four weeks, access to information from Iran's database was blocked due to some political difficulties (December 25th, 2018 - January 16th, 2018). All internet connections to university databases, and to archives, were blocked for outsiders. Therefore, my research could not progress at the time. Thus, I begun to gather general information on subway design and metro planning from available European standards and sources in order to understand the size scale, as well as other elements needed for the subway tunnels.

All of the fault lines in the area have been investigated and their characteristics, with attention to previous studies, have been presented. Quaternary faults in the 1- Major and most seismogenic faults (more than $10 \mathrm{~km}$ long and active) 2- Medium fauts (2 t to $10 \mathrm{~lm}$ long)
3- Minior faults (less than $2 \mathrm{~km}$ long)

3-Minor faults (less than $2 \mathrm{~km}$ long)
Mahdavian, A. (2008). Seismotectonics and Seismic Hazard Assessment of the Sari quadrangle in Iran. Seismotectonics and Seismic Hazard Assessment of the Sari Quad

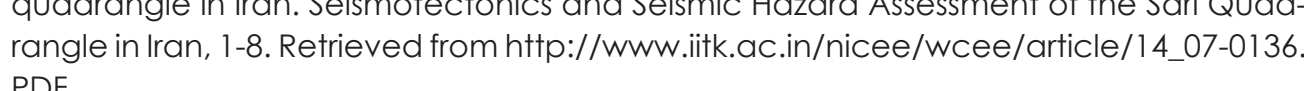


When planning new underground subways and subway tunnels, an optimization of tunnel configuration in terms of operationa safety, life cycle cost, construction schedule, and environmental impact is needed. In general, tunnel design and tunnel technology have been advanced over the past 25 years in such way that it has made it feasible to construct large diameter bored tunnels, which have two parallel tracks going in the same direction rather than one single track for high populated urban areas. ${ }^{20}$

The operational safety parameters for underground subway systems follow different standards and guidelines depending on the country, and where the construction will take place. These standards and safety parameters also change based on whether the design is for a single track parallel tunnel, or a mono-tube double track tunnel. Weather and geological conditions are also taken into account. Regulatory requirements in Tehran and elsewhere, such as in Europe, share a common feature whereby

The purpose of this code is to provide minimum provisions and regu-
$20 \quad$ lations for the design and construction of buildings to resist the effects of earthauakes Through these provisions, it is expected that in major seismic ground motions the loss
of life is minimized while the stability of the building is maintained, and in moderate and low seismic ground motions, the building is left without major structural damage, Version_English.pdf

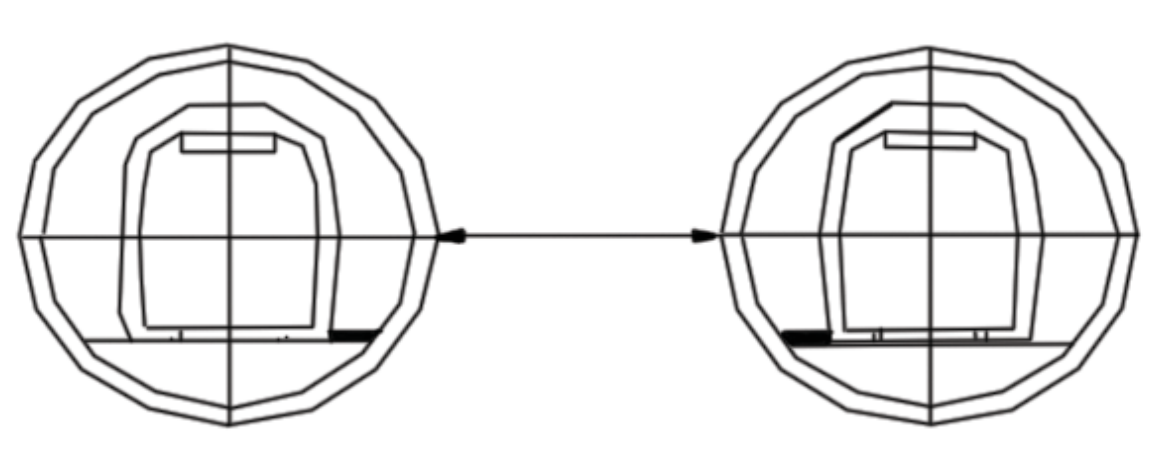

Twin tube tunnel with single track

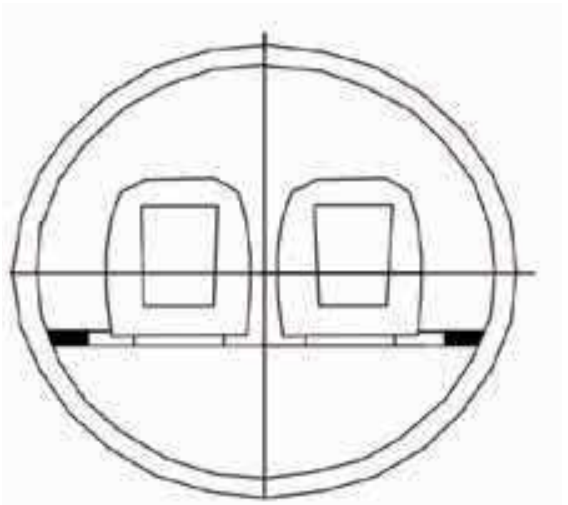

Mono-tube tunnel with two tracks

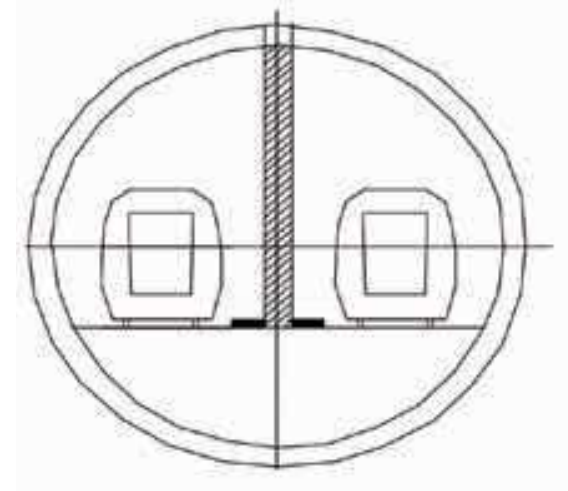

Mono-tube with two tracks and central dividing wall instructions and rules for regional railway systems are different from local regulations. Moreover, safety certification is either given by the transit agency, which is called self-certification, or it is given by a country's laws, which require risk assessment and cost benefit analysis. This is how it works in Iran and this also applies for the capital, Tehran. ${ }^{21}$

\section{Risk Assessment for Tunnel Configuration 22}

There are three different tunnel configurations for the present risk assessment: (1) Twin tube tunnel with single track, (2) Monotube tunnel with two tracks, and (3) Monotube with two tracks and a central dividing wall for single track twin tube, whereby the central line of the tunnel lines up with the center line of the tracks. The structure is usually made of precast concrete segmental lining There will be a pedestrian passageway provided in the inner side of the subway tunnel wall according to the direction of movement. There will also be cross passageways in between tunnels for safety and way finding for the pedestrians.

When safety tests are being done, they need to be performed at a reason-
21
able cost and all risks need to be as low as reasonably practicable, which is short for able cost and all risks need to be as low as reasonably practicable, which is short for
ALARP.

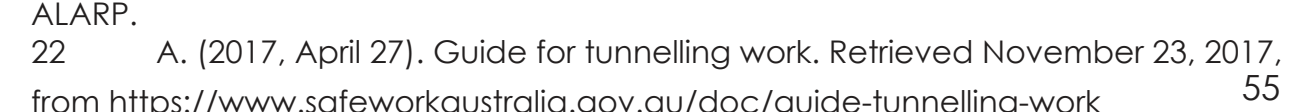


A typical monotube with a double track placed side by side is constructed is precast concrete segmental lining with no central wall. The tunnel central line is located between the two tracks and the pathway for pedestrians, which is in the inner side of the tunnel walls on either side. For safe access to the surface, there will be shafts provided to bring light into the space and also provide access to the surface for pedestrians. ${ }^{23}$

A mono-tube tunnel with a vertical central dividing wall, which is like the monotube with two tracks, but has a central wall between them. In this case, the central line of the tunnel is aligned with the center line of the central wall.

The underground facility of the Mizunami Laboratory (MIU) ${ }^{24}$ is one of the nuclear facilities that was constructed deep underground for nuclear development activities in Japan. This facility performs research experiments on geological disposal technologies for high level radioactive wastes. To perform these experiments, shafts were excavated deep underground in order to as$\frac{s i s t}{23}$ TBM tunneling in mixed-face ground: Problems and solutions. (2015, June 26).
Retrieved April 05, 2018, from hitps://www.sciencedirect.com/science/article/p/pi// 2205268615001020
Elit Delete

24 Edit Delete

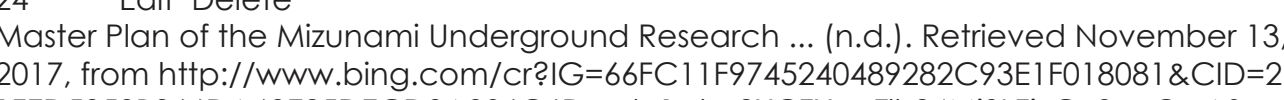

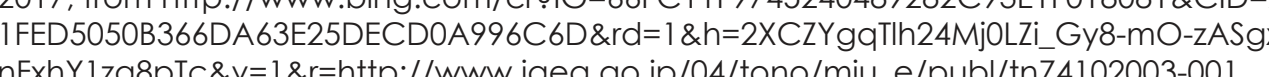

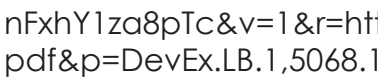

in the development of the public's understanding of the deep geological environment. This massive construction has a depth of up to 1000 meters. This study is of interest as a precedent to this thesis topic because it demonstrates how to construct mega structures underground with consideration of:

1. Site conditions

2. Topography and geology

3. Investigation and research plan

4. Materials and equipment to be brought in

5. Entrants

After researching the methods, the risk factors need to be taken into considerations. For instance, fire is one of the major hazards that can occur in the underground tunnels. In case of a fire, there needs to be a secondary, or tertiary tunnel, which has access to the surface for people to escape. A secondary option could be a safe fire compartment space within 2 tunnels, which can accommodate a significant number of people. Earthquakes are another potential hazard. They threaten underground structures. 


\section{Construction Methods}

Excavation methods 25

There are many different methods when it comes to excavating tunnels and shafts. There are three major excavation methods: the short step method, the long step method, and the mechanical excavation method. For projects that require excavation in poor rock masses, the short step method is more useful because it applies blasting and lining repetitively at short intervals. This method enables excavation at high and advanced rates. Mechanical excavation methods require a pre-existing tunnel structure which will be suitable for this thesis. Since I am going to add my design as an extension to the pre-existing or under construction tunnels, the mechanical excavation method is chosen. The amount of time each technique requires is dependent upon the depth of the tunnels. The deeper the tunnel, the more time is needed. One of the many risk factors while excavating tunnels is the unexpected ground inflow, which needs to be taken into consideration.

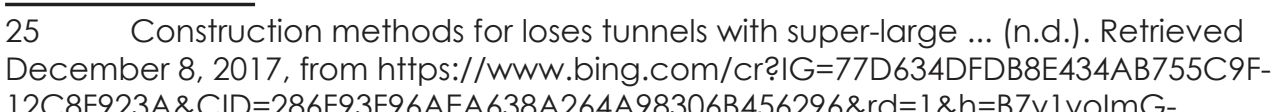

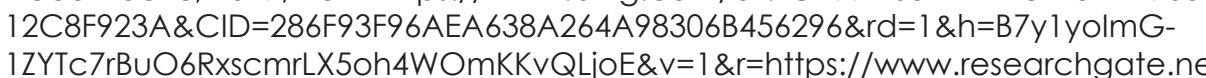

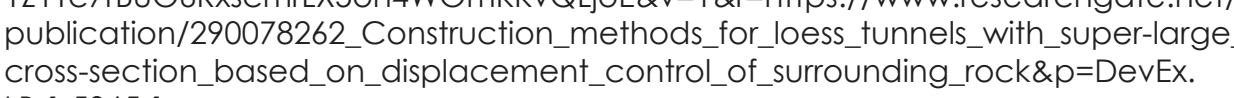


Selected
in Detail

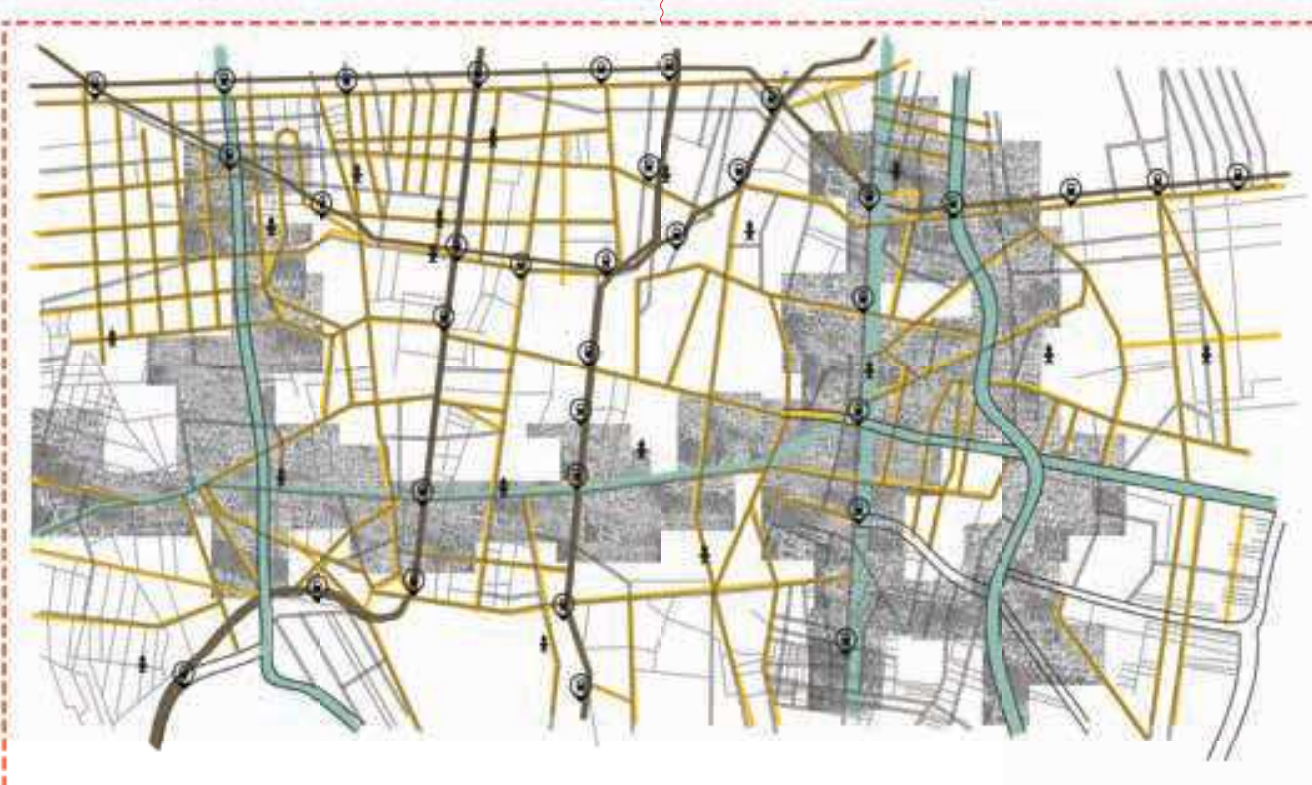

Detailed View of District 12

Underground subway lines

above ground is shown in the

-

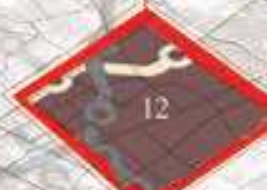

District 12 was chosen desig

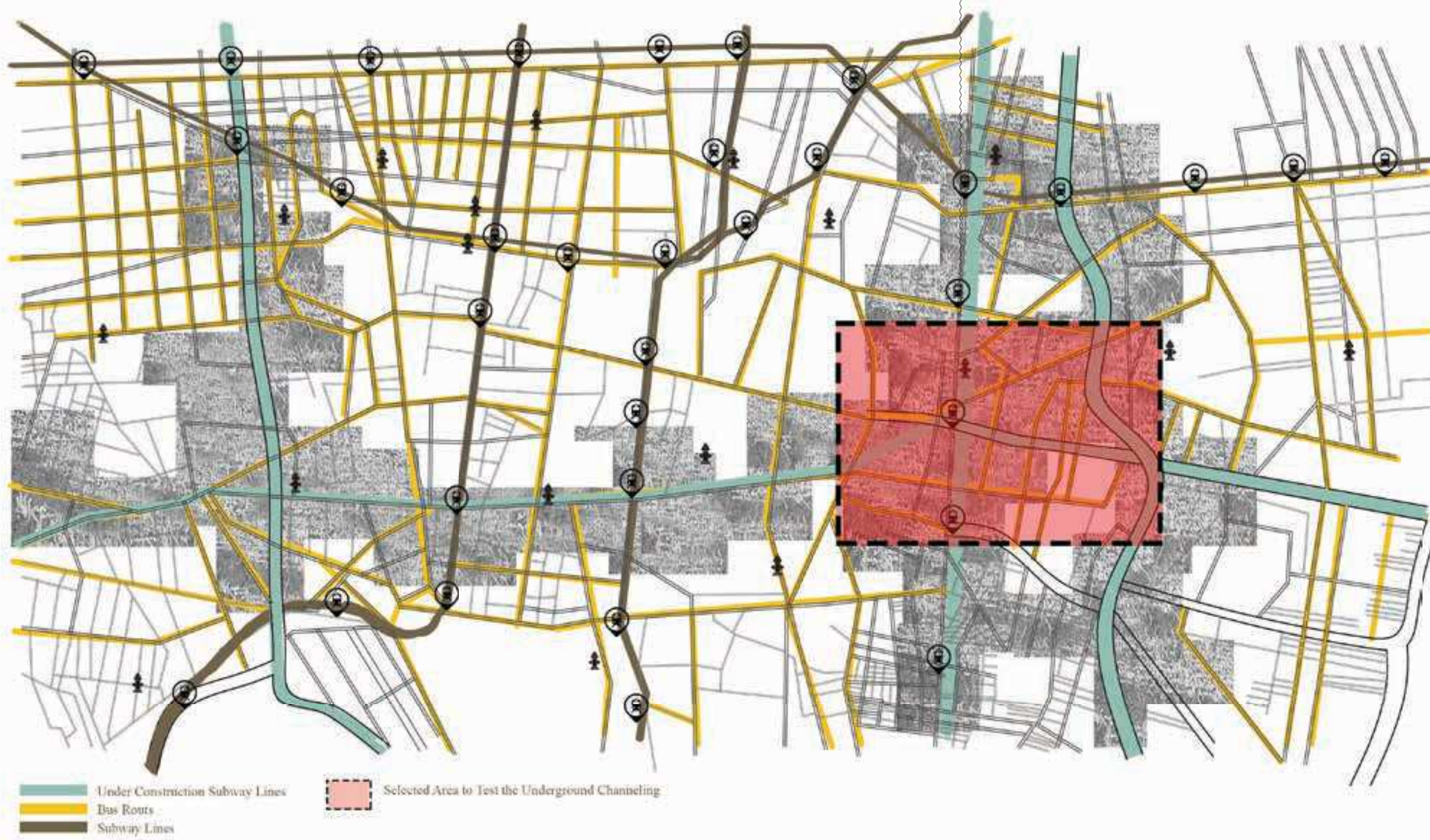


The Vision of District 12, Tehran Iran

Representing subway stations, fre stations and transportation systems within this district.
Representing the underground fictional metropolis as an overall vision.

.

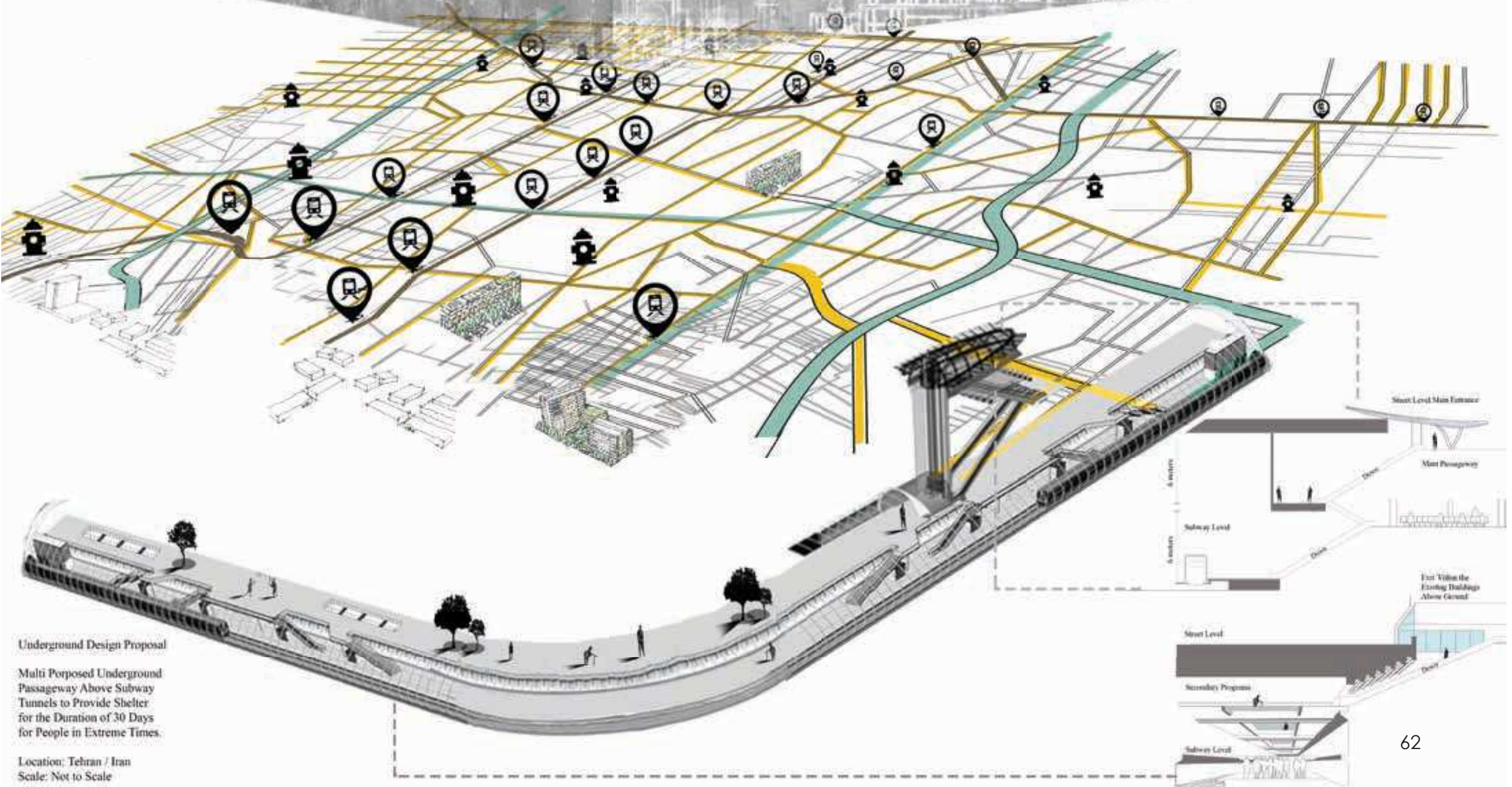

Design Strategy

The research process led me to make the decision to add extra levels to the new subway lines that are presently under construction. The subway level is currently located at 18 meters below ground. The height of the subway interior space is 3 meters. In or der to add another level on top of the tunnel one would need to have at least 3 meters of height above the subway, which adds up to 6 meters in height.

Therefore, my design will be located at a depth of 12 meters below ground or 3 meters above the subway train. This level will contain the passage way from point $A$ to point $B$. It allows for people to be able to commute by walking underground daily and in cases of emergency, it can also be used as a shelter. The underground experience is designed to be a special journey. This makes it possible for people to be able to use it every day, rather than leave it as an underground space, which will never be used or will only be used in times of crisis. Therefore, to make this journey special, I plan to have some of the common everyday activities happen along this journey. Through the design drawings, I show a portion of this journey, which could be expanded, applied, and in parts repeated throughout the subway connections. 

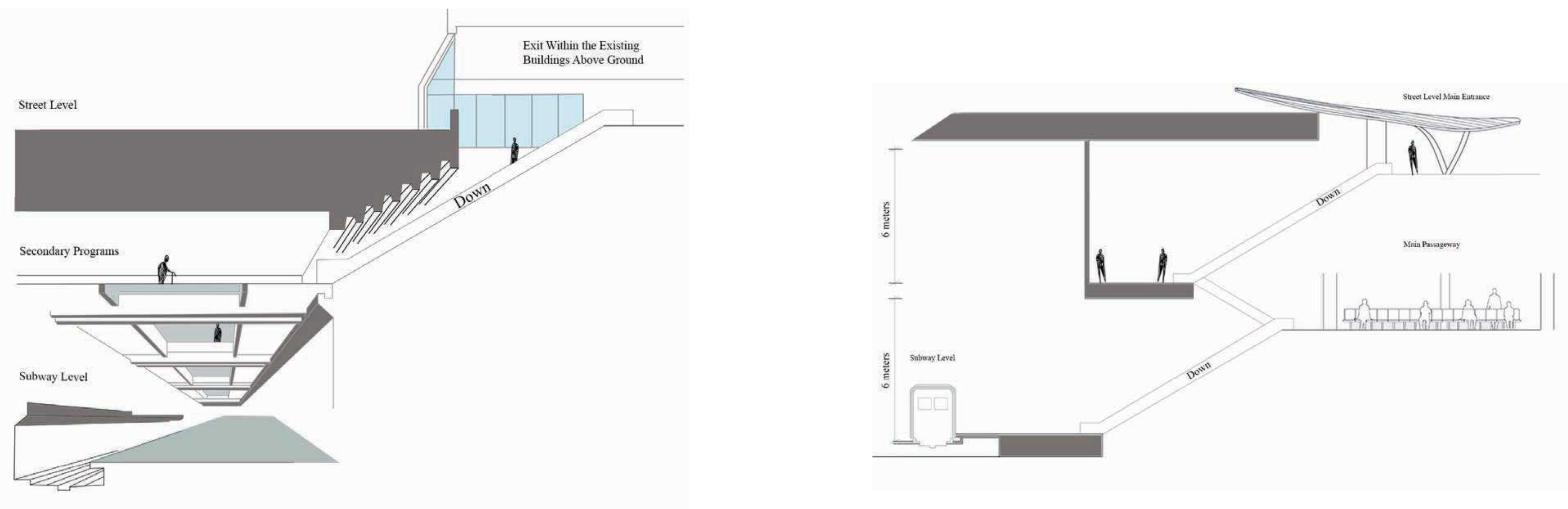


\section{The Idea In Mind}

The Underground Subway System with the Extension Sub connection added. (Final Design in Progress)

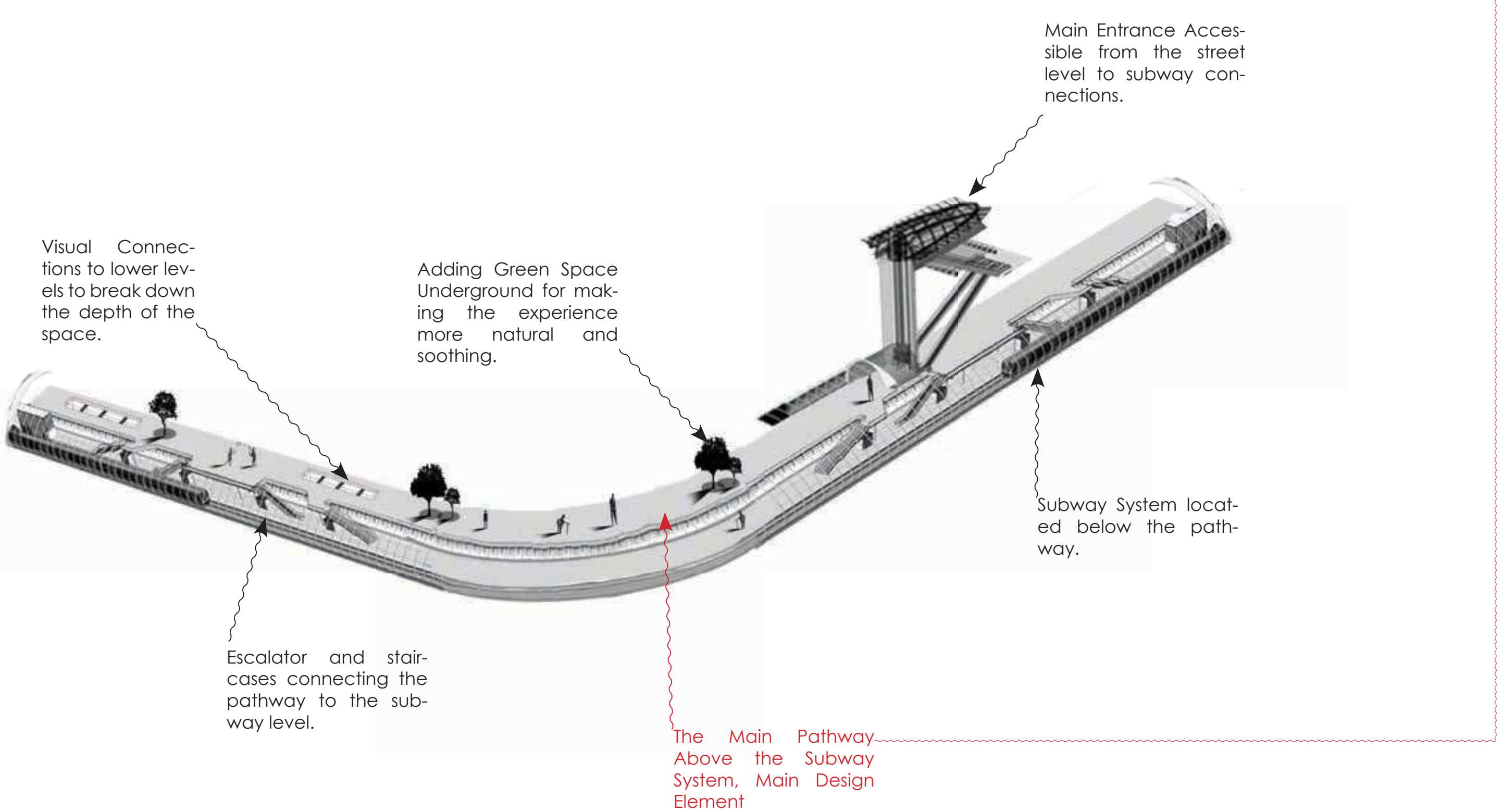

Above the Subway
System, Main Design
Element
This main passageway can also be useful when it is extremely hot, or cold outside. People could use the underground passageway to commute and protect themselves from extreme weather conditions. From the main walkway, which is located on top of the subway train that is under construction (12 meters below ground) there will be pods elevated from the main pathway, 6 meters above the main passageway ( 4 meters below ground), which will contain secondary programs. These secondary programs can be transformed into a primary program in times of emergency, providing shelter, communal spaces, clinics, etc. The interior layout, settings, and furnishings are specifically arranged and designed in such way that they perform in multiple functions. For instance, the cafe areas and the mini library can easily be transformed into sleeping areas. Children's play areas will remain as such, thus minimizing the sense of displacement that they would experience, when living underground. The library can be used as a mini school, etc. There will be a need for a small clinic, but I have not developed that part of the program in the 
sample section of the project, since it constitutes a special program that would require additional design considerations and research beyond the scope of the thesis.

There will be additional emergency exits used in times of crisis, in case the main entrances and exits become blocked. For the population's protection, I have decided to have these emergency exits hidden within buildings on the ground so that they will not be visible and will not become possible targets. Through the drawings I show the different program areas as possibilities and potentials, which could be easily transformed in times of need.
Finalized Design Layout

Level - I (4m below grade)
Secondary Programs

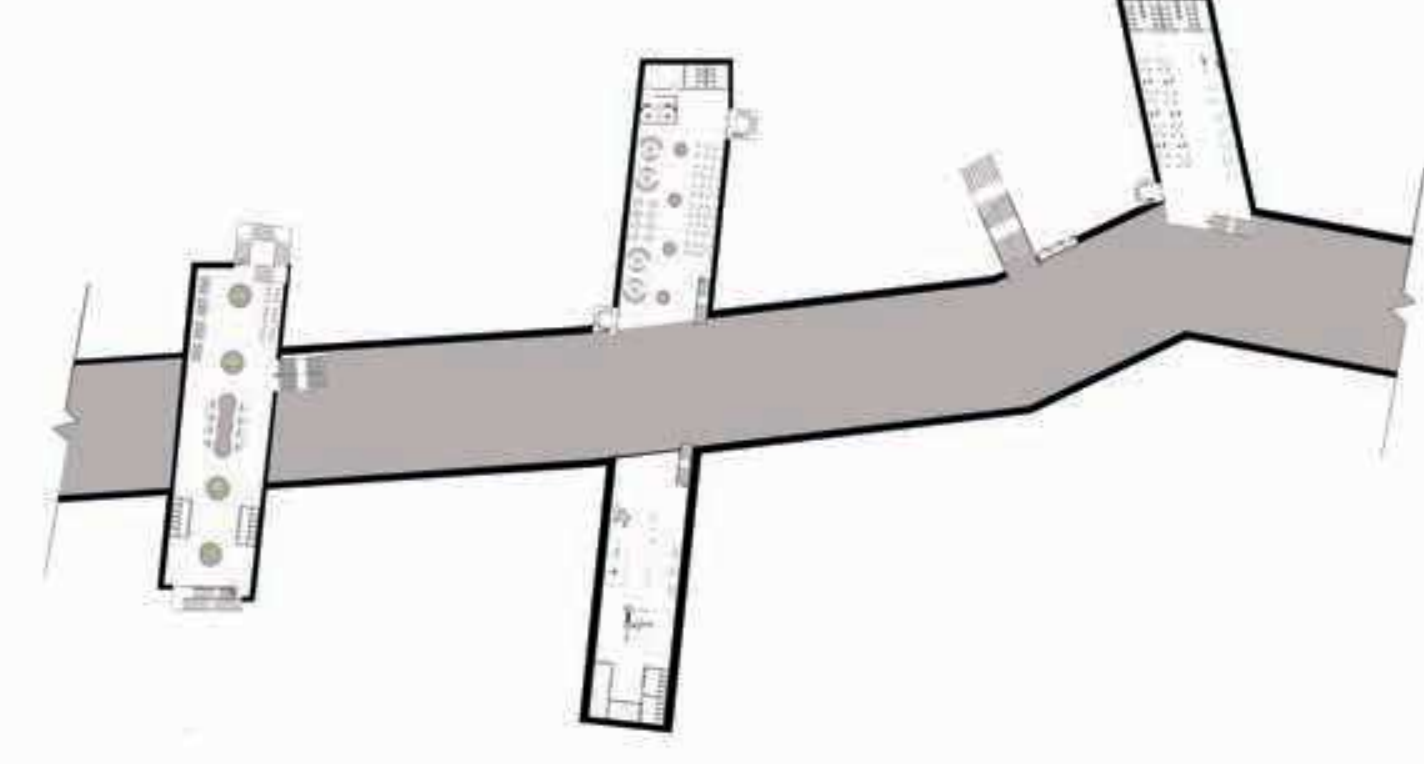

Level $-2(12 \mathrm{~m}$ below grade)
Main Passageway

Notto scole

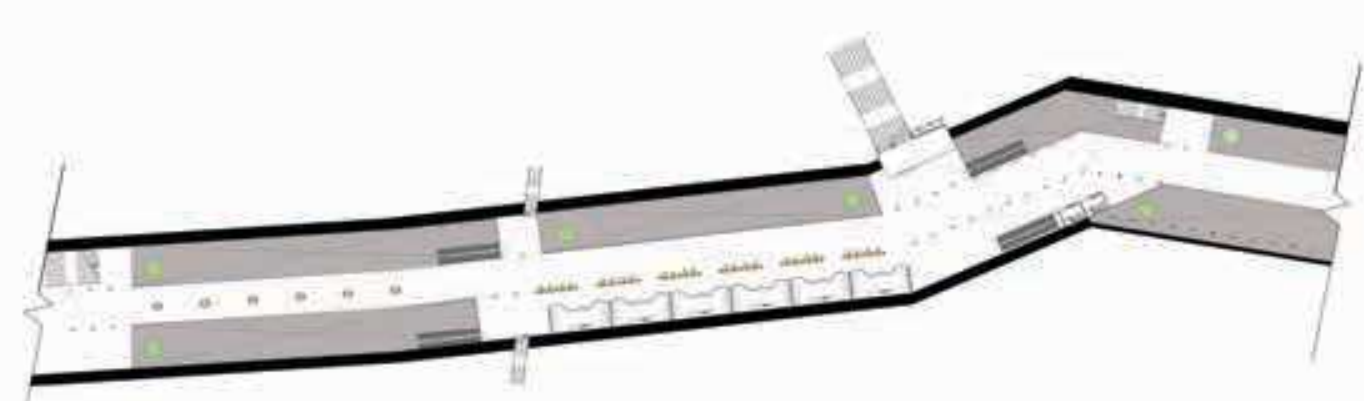

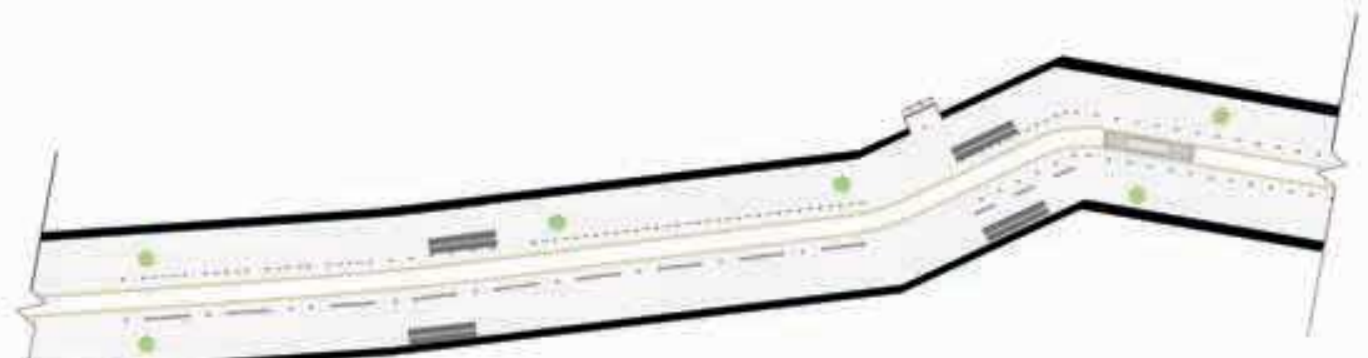


To make the underground space an ordinary experience, the need for natural light is required. Therefore, in the research process a technology came to interest in order to transfer the natural sunlight to underground space.

The technology requires:

Solar collector dish, tracking mechanism (irrigators),

helio tube, and dome (distributors).

These Solar Collector dishes designed by James Ramsey of Raad Studio is called "The Remote Skylight". ${ }^{26}$

In this technology, the sunlight is collected by the parabolic collector, reflected and concentrated at one focal point and get redirected underground. Then by the use of the reflective dish underground the collected sunlight will get distributed into the space and help the vegetation and the commuters to absorb sunlight.

This technology is designed in such way that it transmits the necessary wavelengths of light needed for plants to photosynthesis and grow. ${ }^{27}$

26 Project. (n.d.). Retrieved January 19, 2018, from hitp:///thelowline.org/about/ 27 prect/
27 Ryn, K. J. (n.d.). The Lowline, the World's First Underground Park, Is Coming
to New York City. Retrieved Jananuary 010, 2018, from https://Www.inc. com/kev-

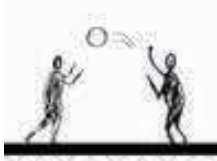

The Remote Skylight

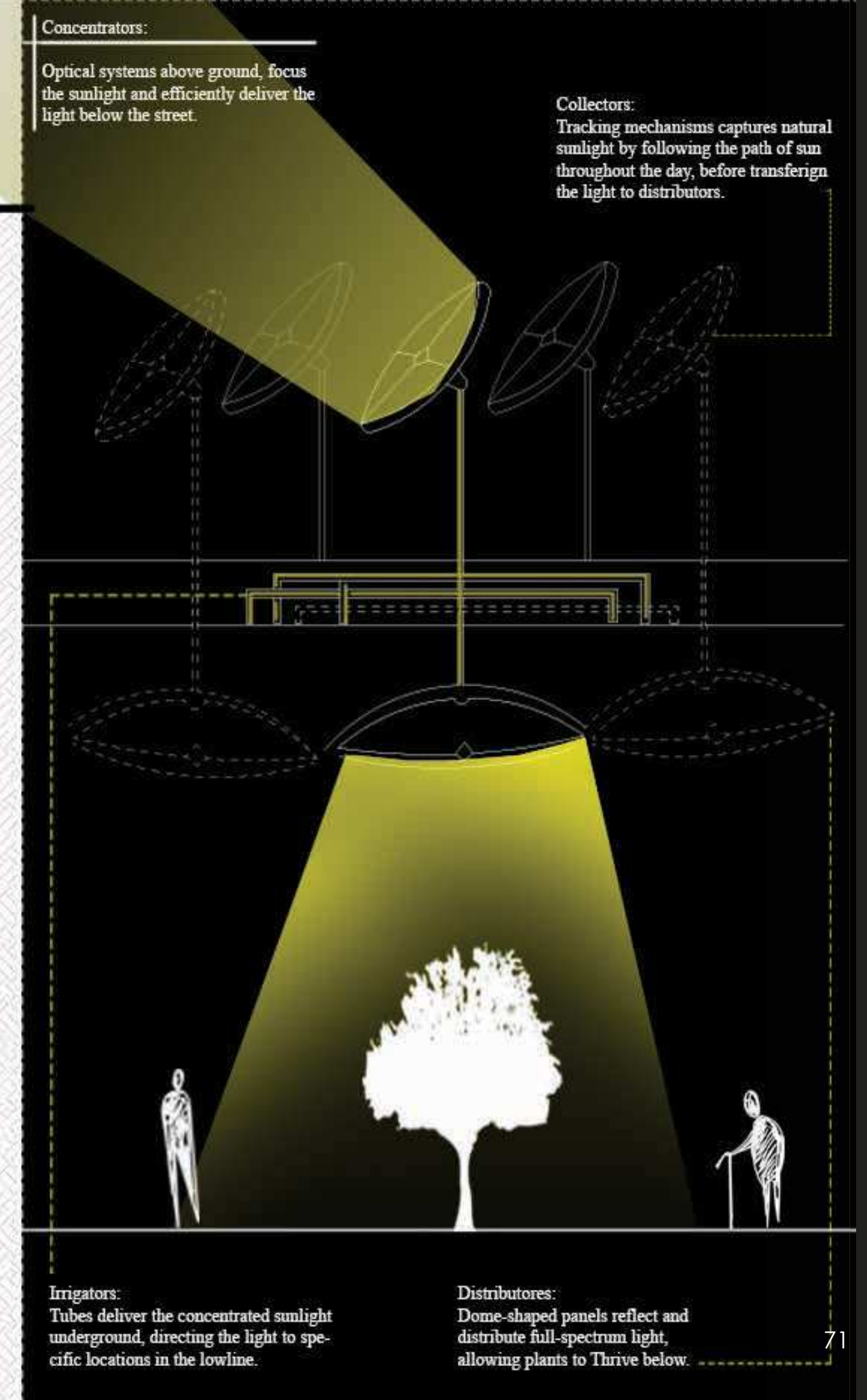




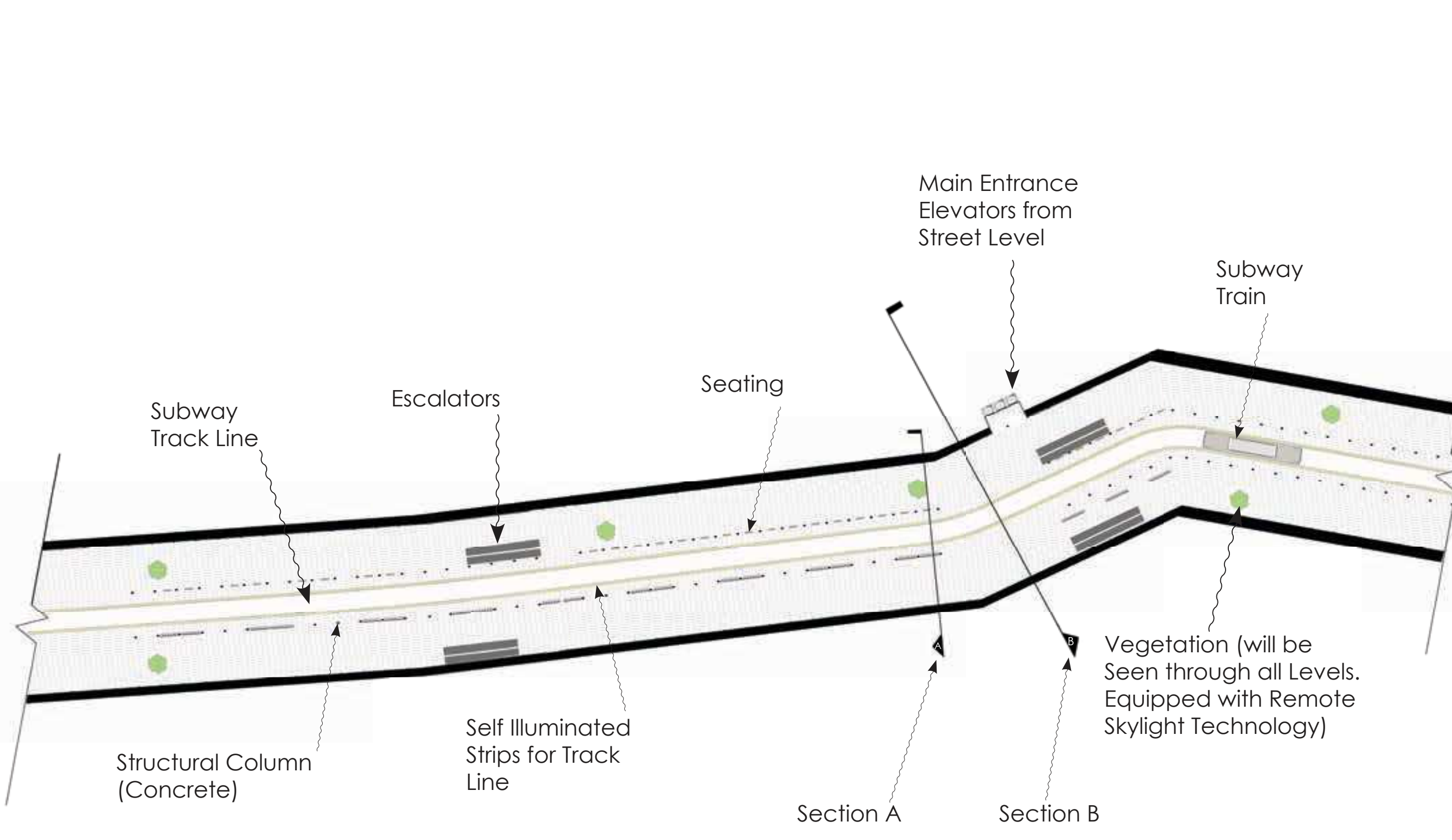

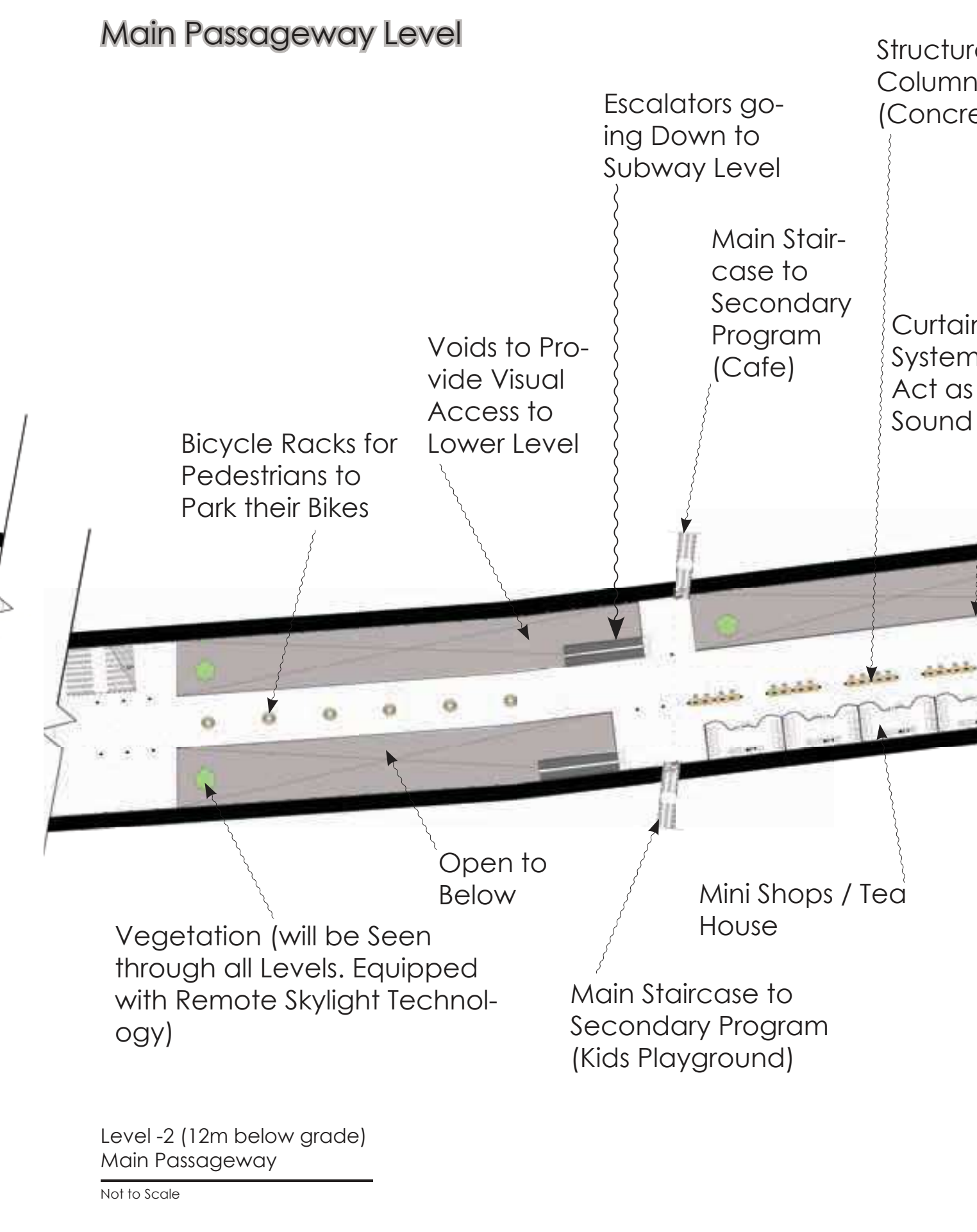

Structural 
Secondary Programs (Multi Functional Programs)

Emergency Exit Staircase,

Buildings on Ground Level
Buing

Section A

Main Stair-

Main Stail-
case to

$\begin{array}{ll}\text { Emergency Exit Staircase, } & \begin{array}{l}\text { Voids to Pro- } \\ \text { vide Visual } \\ \text { Exiting Within the Existing }\end{array}\end{array} \quad \begin{array}{ll}\text { Main Entrance } \\ \text { from Street Level }\end{array}$

$\begin{array}{ll}\text { Buildings on Ground Level } & \text { Access to } \\ \text { Lower Level }\end{array}$

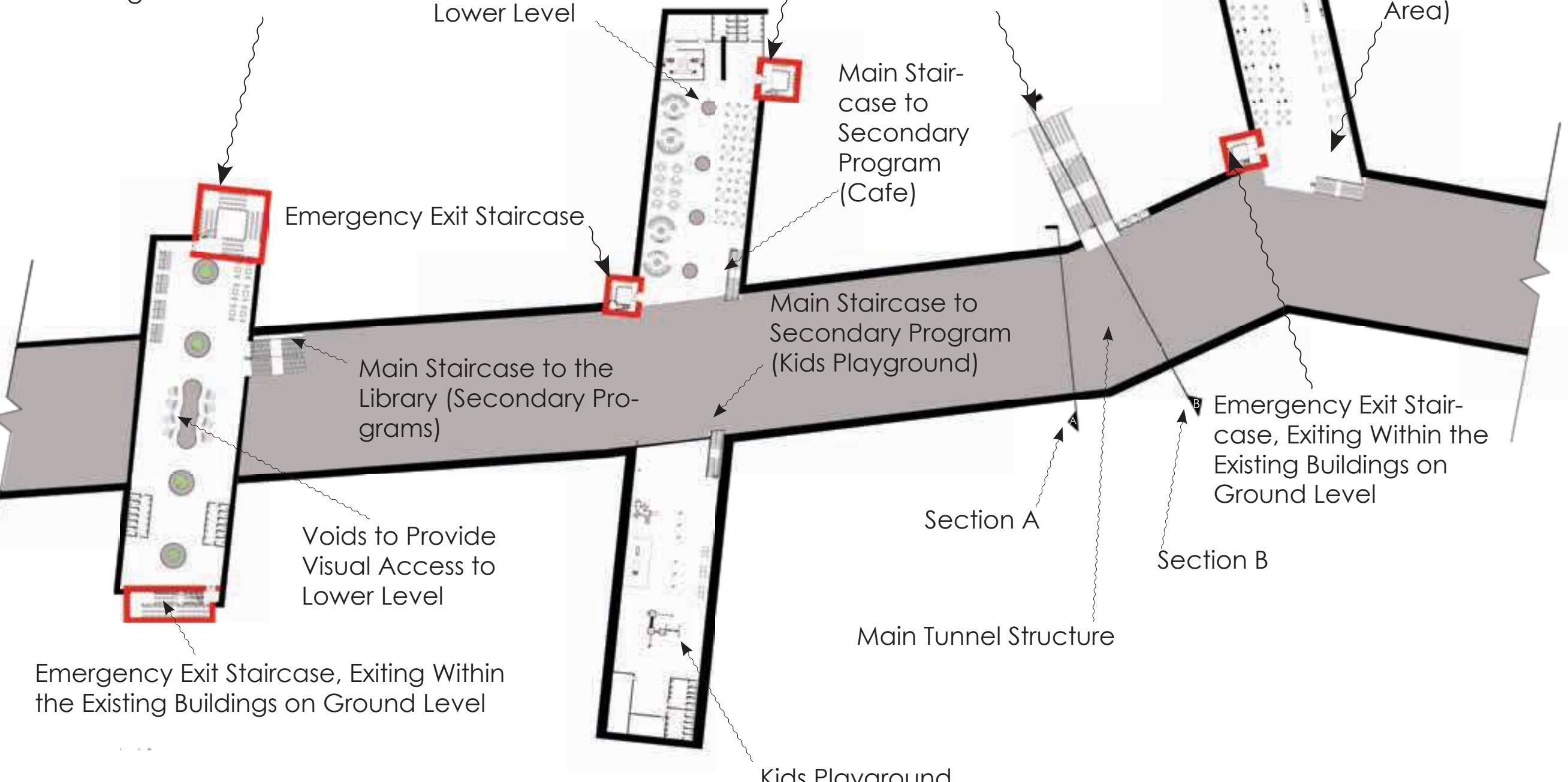

Kids Playground
Remote Skylight Technology

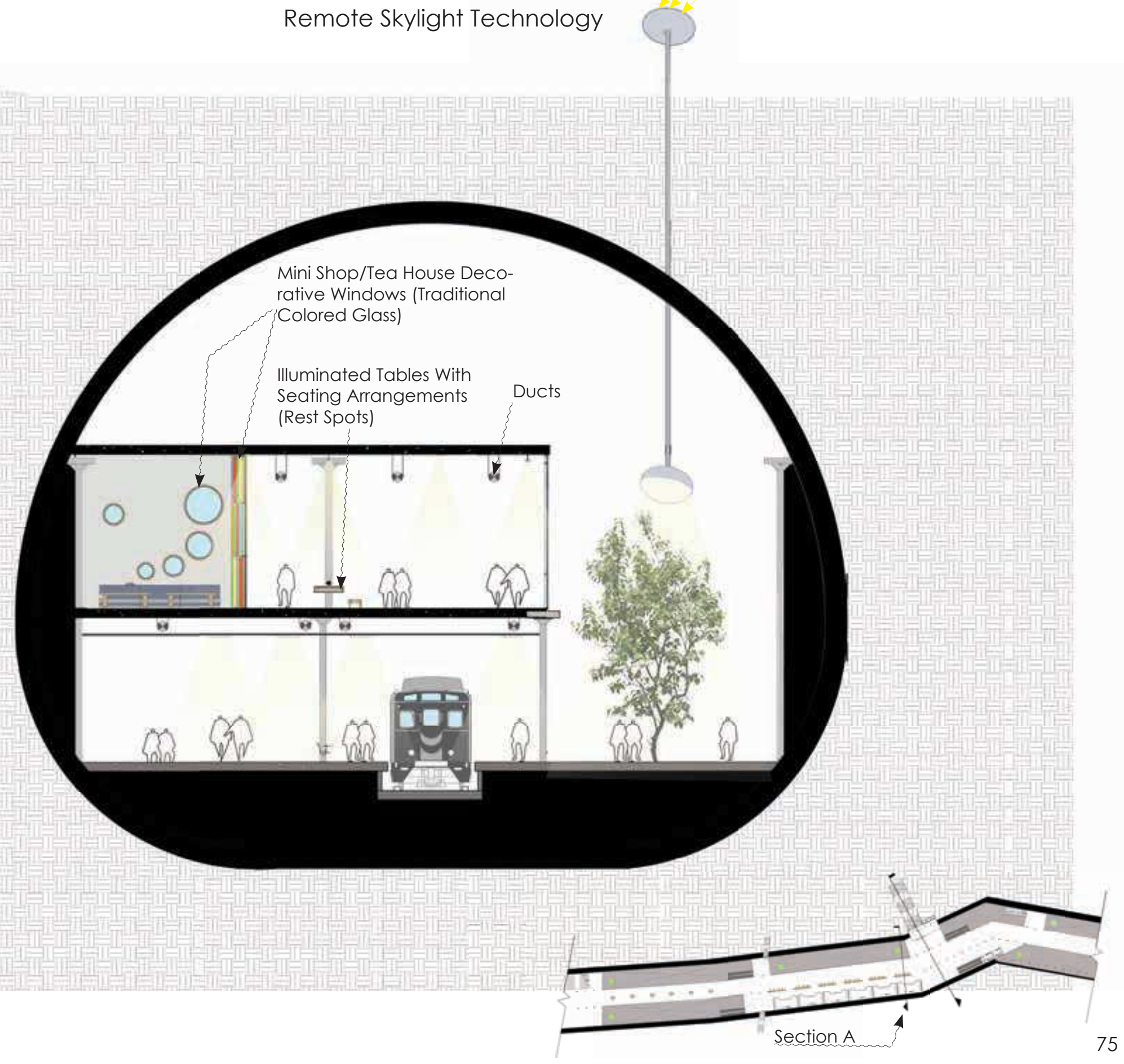




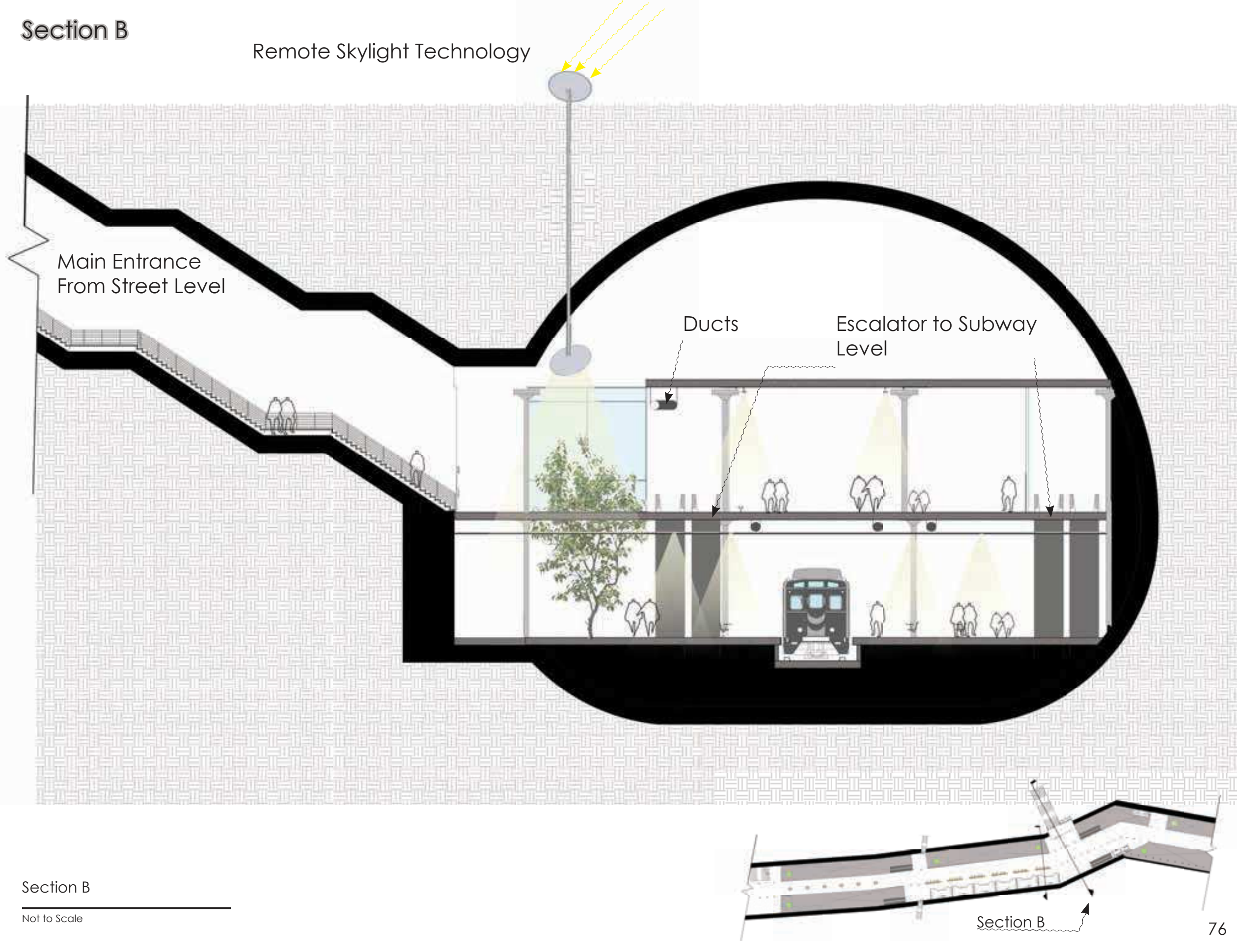

Axonometric View

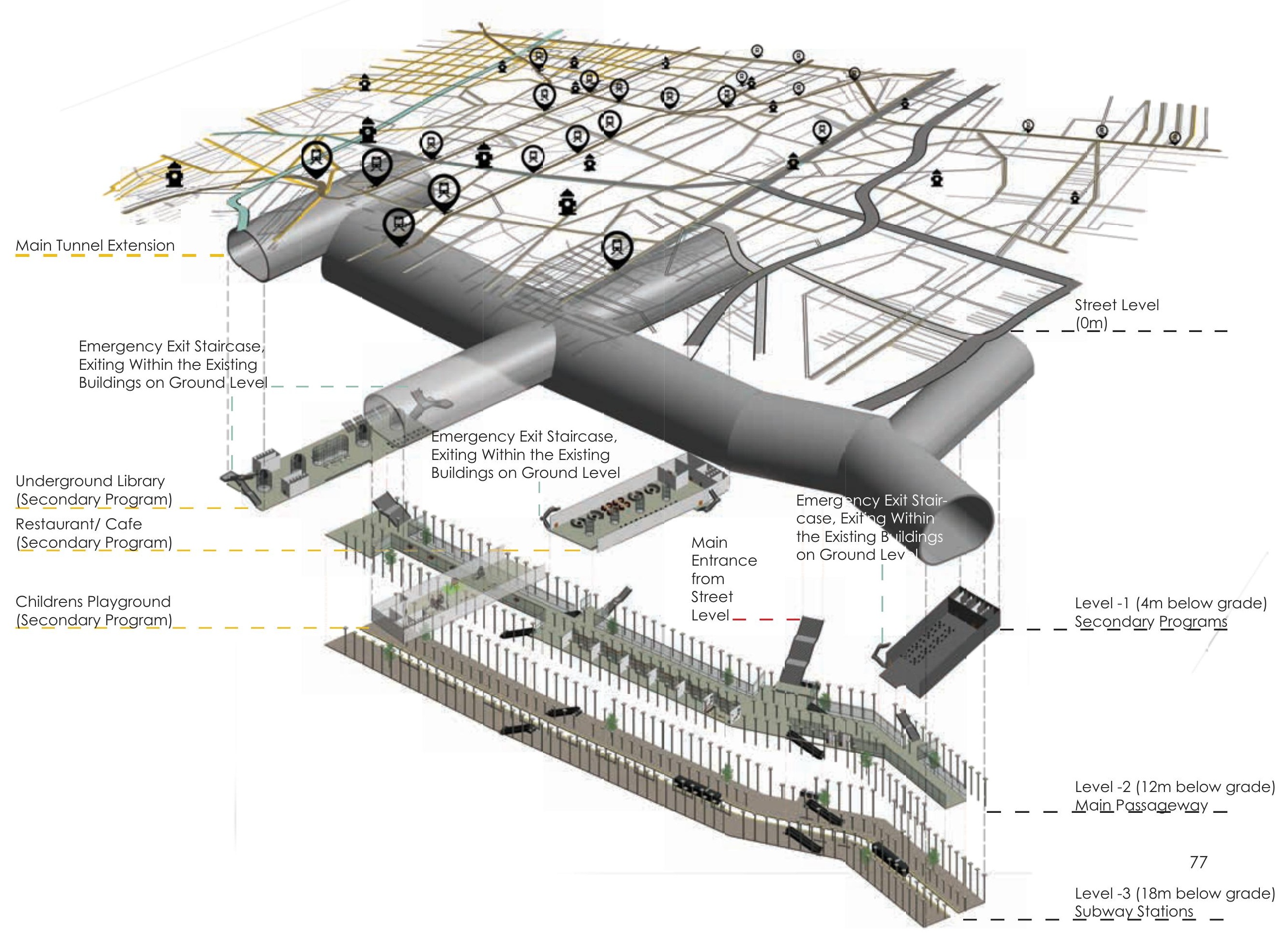




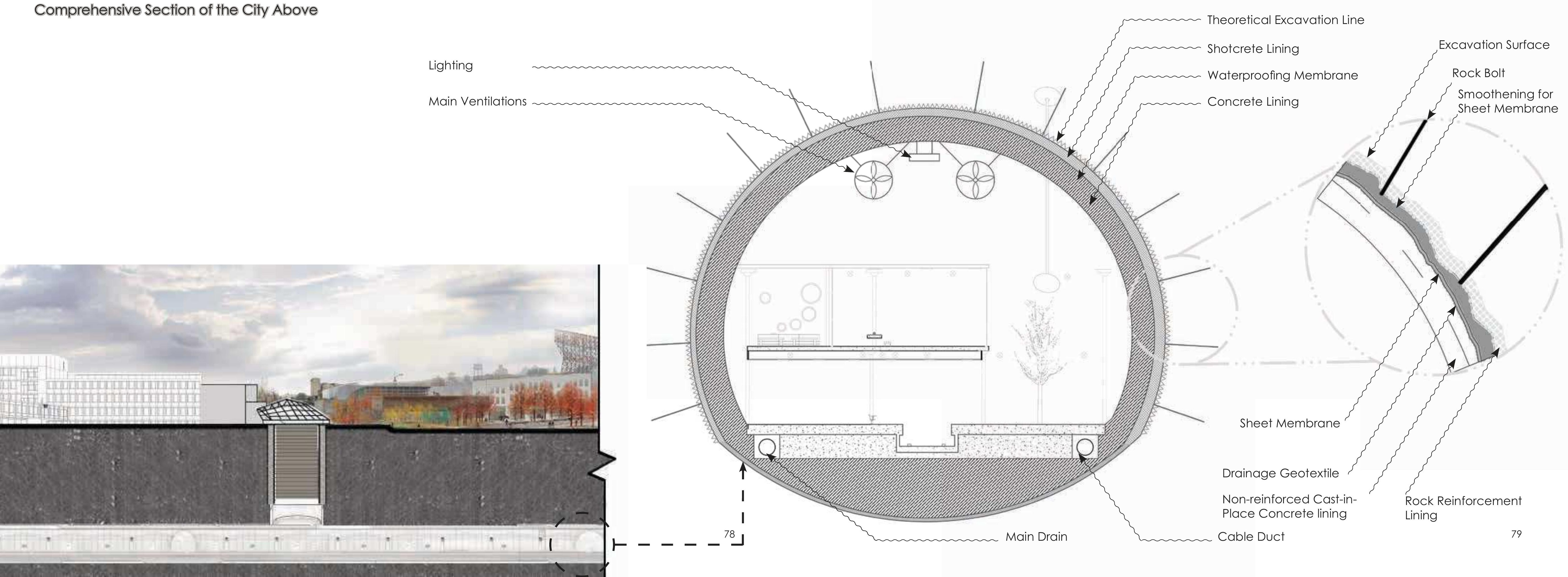




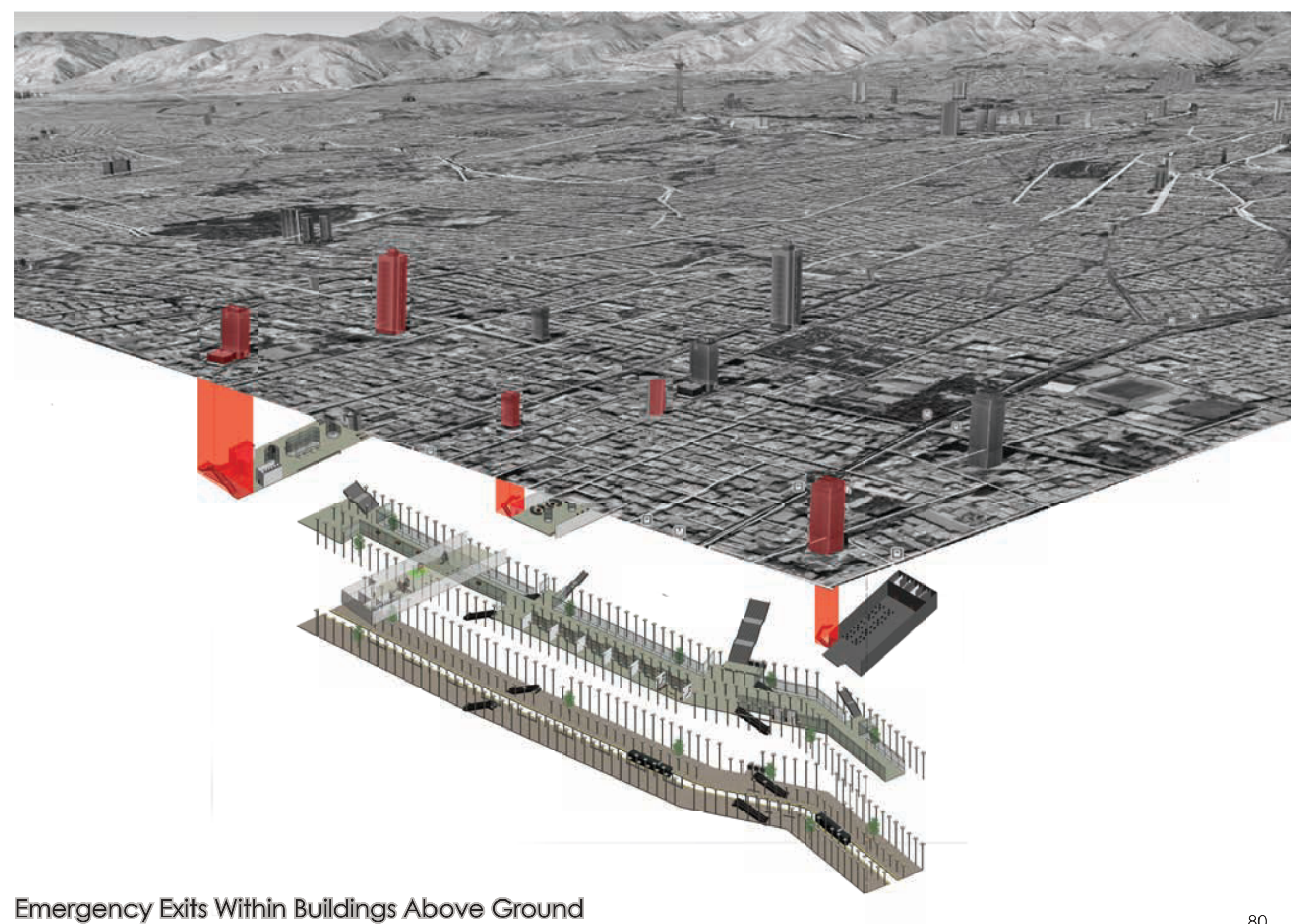

The Underground

Experience 

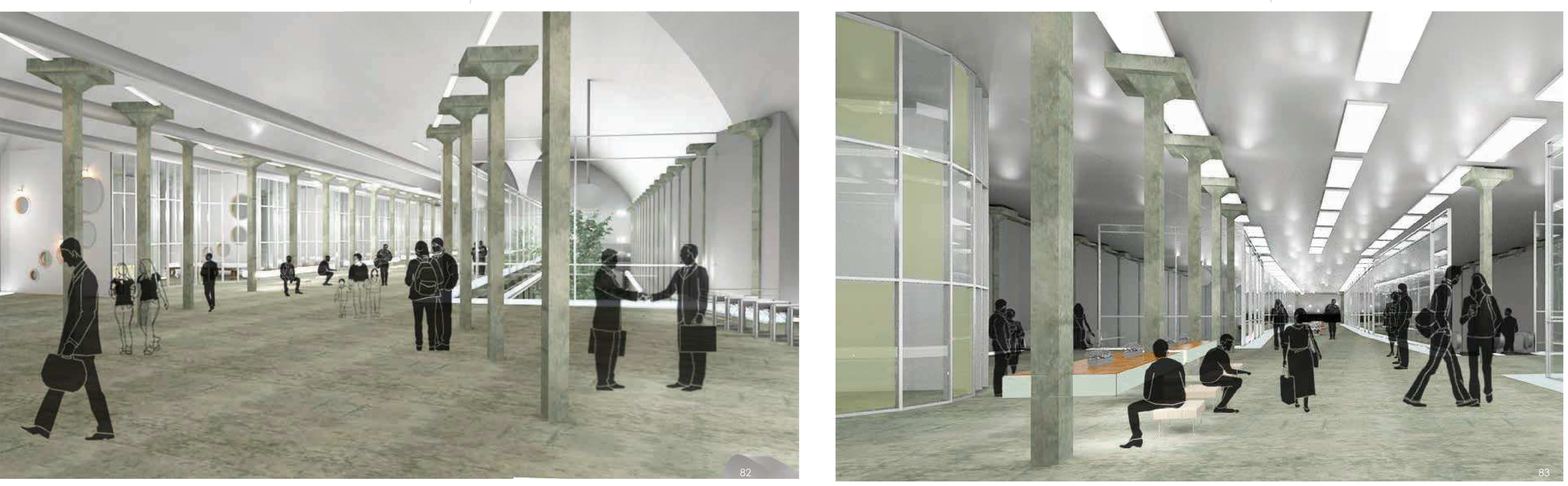


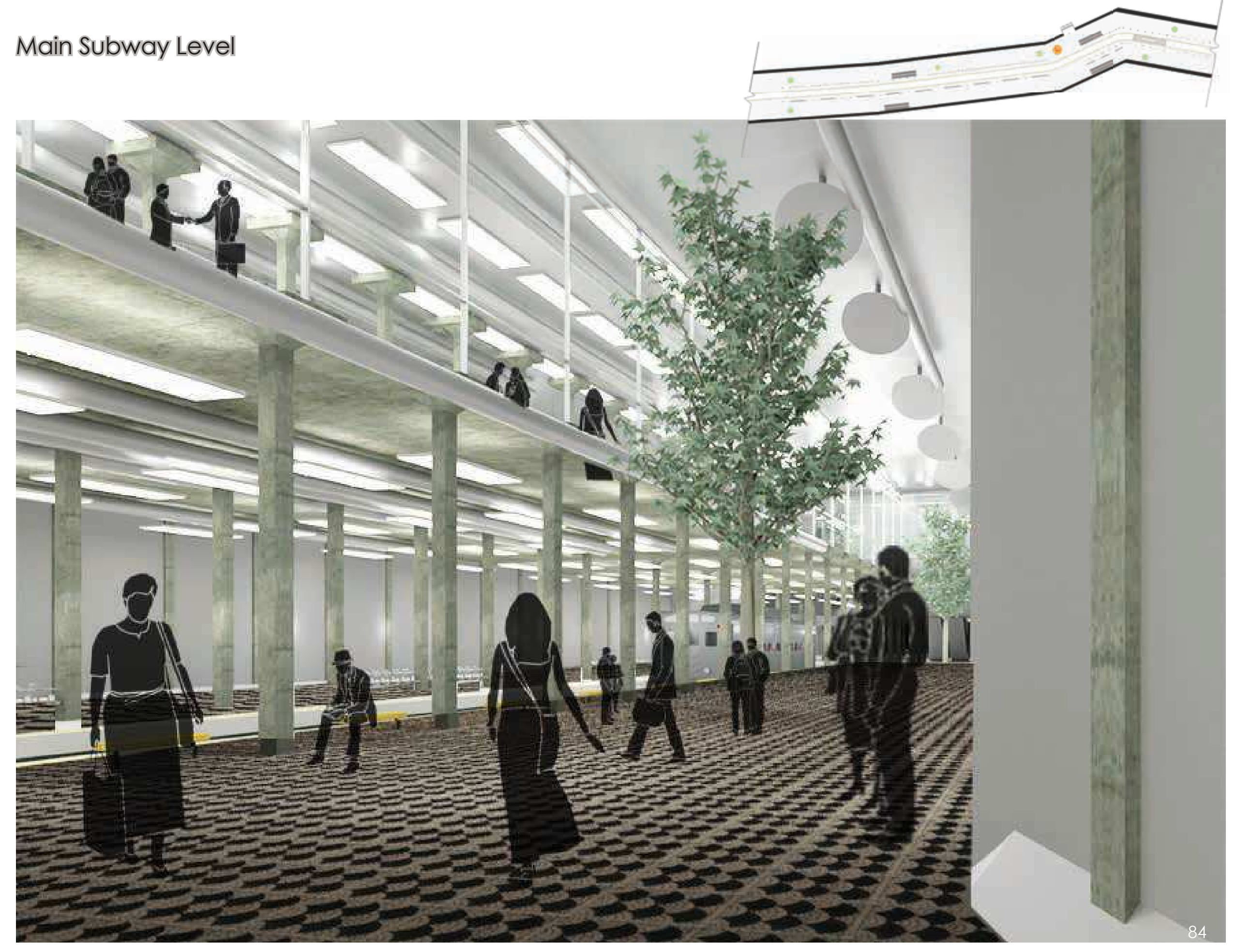

Main Passageway To Library $=2$

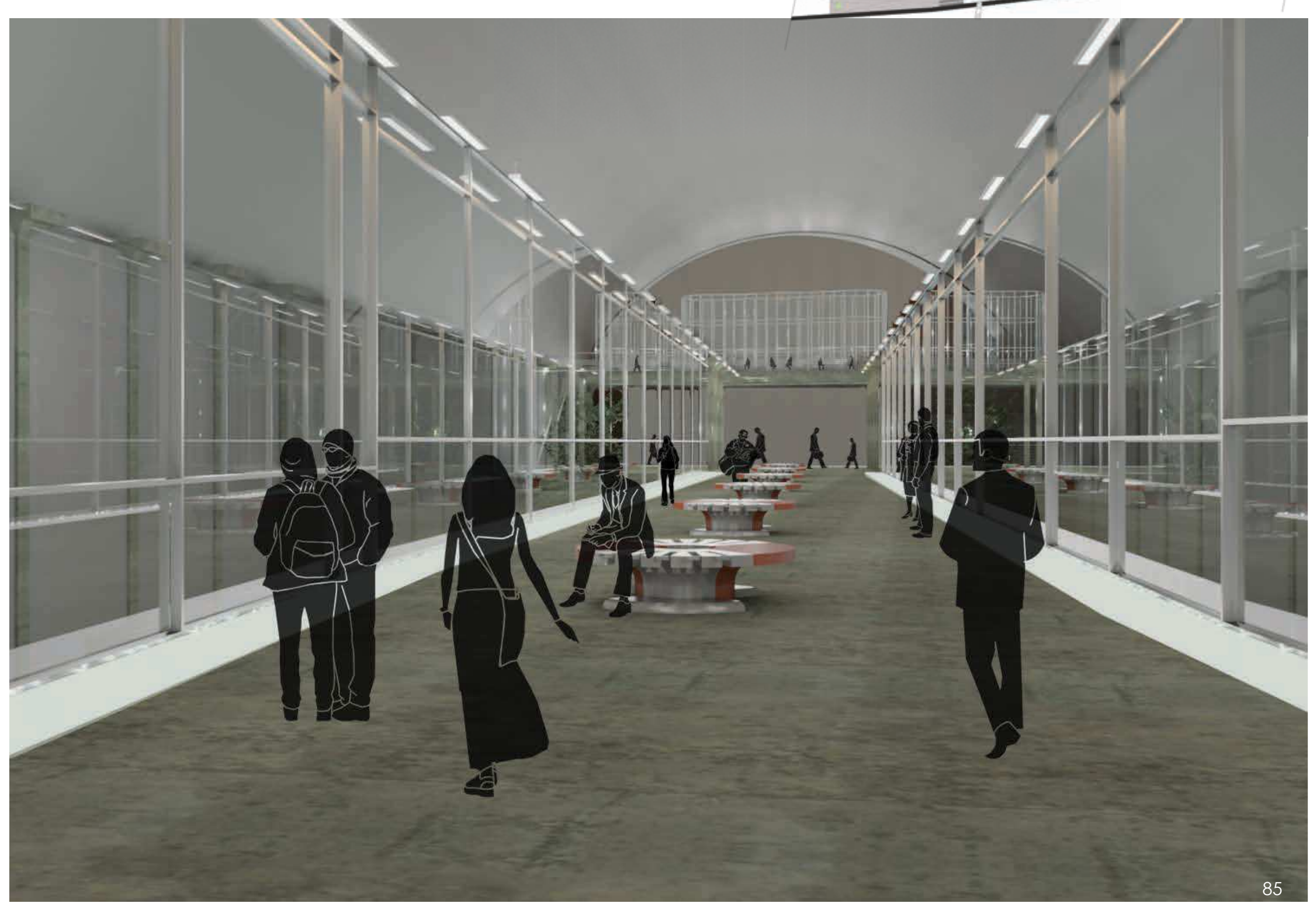




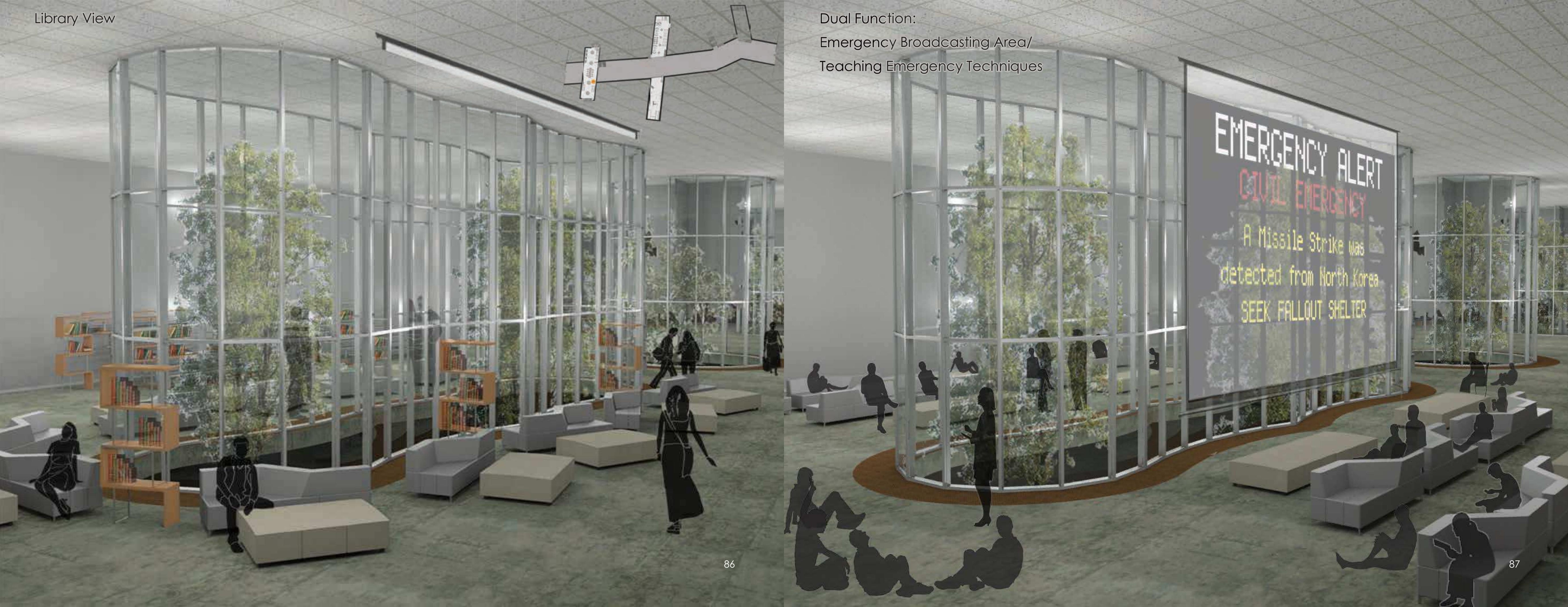



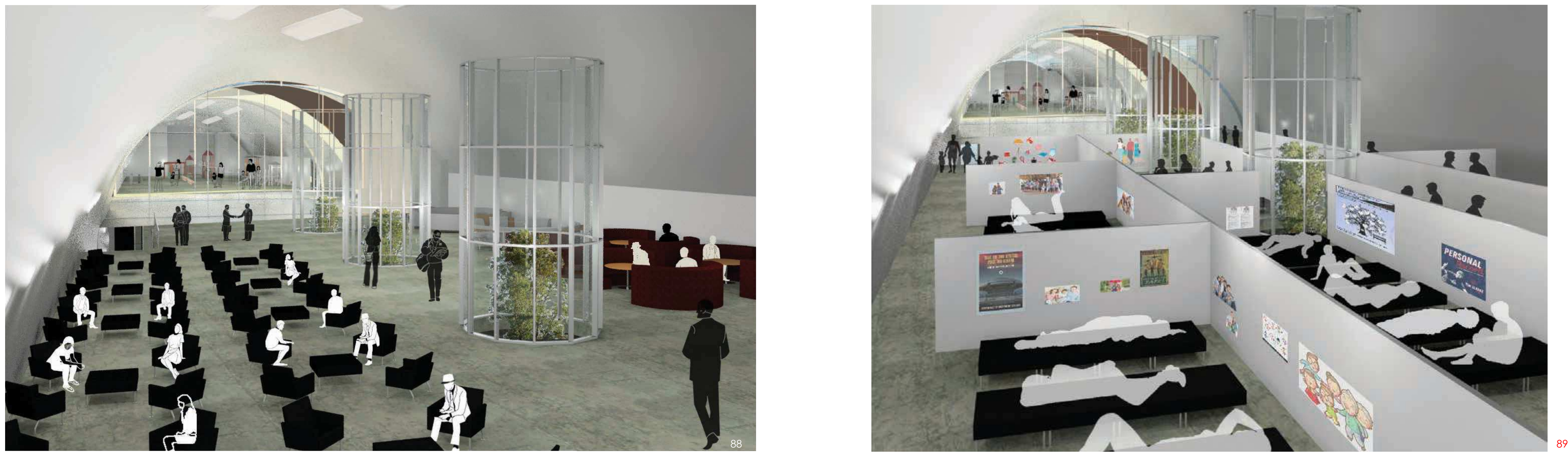
There are many forms of temporary or emergency dwellings for people. The focus of this thesis was to provide people with a temporary dwelling in times of duress which can be functional andbe used everyday.

This thesis examines the possibility of channeling multiple existing or under construction subway tunnels while adding extensions to it in the city of Tehran. This vision will eventually create an alternative underground metropolis for times of crisis, which can help the individuals who choose to stay in the city during a time of crisis, due to complications, or necessity.

Furthermore, this thesis provides a design that supports individuals through a crisis experience, by making this journey as ordinary as possible when they are faced by emotional challenges. 
Andisheh, Kaveh and Amiri, Gholamreza Ghodrati, "Evaluation of Iranian Code No.2800 for Seismic Resistant Design of Near Source Buildings Based on Real Record of Iran" (2010). International Conferences on Recent Advances in Geotechnical Earthquake Engineering and Soil Dynamics. 6

Andisheh, K., \& Ghodrati Amiri, G. (2011). Evaluation of Iranian Code No.2800 for Seismic Resistant Design of Near Source Buildings Based on Real Record of Iran. Evaluation of Iranian Code No.2800 for Seismic Resistant Design of Near Source Buildings Based on Real Record of Iran, 20(2). Retrieved from http://scholarsmine.mst.edu/icrageesd/05icrageesd/session03/6/?utm_ source=scholarsmine.mst.edu/icrageesd/05icrageesd/session03/6\&utm_medium=PDF\&utm_campaign=PDFCoverPages

Fallahi, Pontia. "The 10 Most Impressive Buildings in Tehran." Culture Trip, 28 Jan. 2017, theculturetrip.com/middle-east/iran/articles/the-10-most-impressive-buildings-in-tehran/.
Susan Sims on December 5, 2017. "Six Modern Buildings You Won't Believe Are In Tehran, Iran." All That Is Interesting, 5 Dec. 2017. all-that-is-interesting.com/tehran-architecture\#4.

Team, FarsiNet Inc. Web. "Tehran: Iran's Capital and Largest City." Tehran - Capital \& Largest City of IRAN - History of Tehran.

Tehran 24, Tehran Weather, Tehran News, Azadi Square in Tehran Tehran Upcoming Events, www.farsinet.com/tehran/history.html. "Tehran, the City of River Valleys, Needs a Landscape Ecological Approach to the Design and Planning of Its Waterways - The Nature of Cities." The Nature of Cities, 16 Nov. 2016, www.thenatureofcities.com/2014/07/16/tehran-the-city-of-river-valleysneeds-a-landscape-ecological-approach-to-the-design-andplanning-of-its-waterways/.

Reports For Tehran - Pedro Ortiz Online, www.pedrobortiz.com/ display-articles/listforcity/city/202./;p. 
"Tehran, the City of River Valleys, Needs a Landscape Ecological Approach to the Design and Planning of Its Waterways - The Nature of Cities." The Nature of Cities, 16 Nov. 2016, www.thenatureofcities.com/2014/07/16/tehran-the-city-of-river-valleysneeds-a-landscape-ecological-approach-to-the-design-andplanning-of-its-waterways/.

Weissmann, Dan. Iran, www.subways.net/iran/Iran.htm.

"Urban Growth." Natural International, 23 May 2012, naturalinternational.wordpress.com/2012/05/23/urban-growth/.

Dehghan, Saeed Kamali. "Tehran's towers: how the Iranian capital embraced bold architecture." The Guardian, Guardian

News and Media, 27 Sept. 2016, www.theguardian.com/cities/2016/sep/27/tehran-iran-bold-architecture.

"First Page - BBC Persian." BBC News, BBC, www.bbc.com/persian.

U.S. Department of State, U.S. Department of State, history.state. gov/milestones/1937-1945/tehran-conf.
Tehran's City Hall. (n.d.). Retrieved March 29, 2018, from http:// statistics.tehran.ir/Default.aspx

Building on the Strength of Iran's Infrastructure. (2017, August 08). Retrieved December 29, 2017, from https://dearinassociates. com/building-on-the-strength-of-irans-infrastructure-2/

Madanipour, A. (2018, March 13). Tehrān. Retrieved November 10, 2017, from https://www.britannica.com/place/Tehran/Cultural-life

Erdem, Y. (Ed.), Solak, T. (Ed.). (2005). Underground Space Use. Analysis of the Past and Lessons for the Future, Two Volume Set. London: CRC Press.

Kurt Evans, Iben Haffner and lan Mills, (2012) Agency. Perspecto 45. MIT Press.

Till, Jeremy. (2009) Architecture Depends. MIT Press. Woods, Lebbeus. Pamphlet Architecture 15: War and Architecture. Princeton Architecture Press. 
Boyd, Gary and Linehan Denis. (2016) Ordnance: War + Architecture \& Space. Routledge.

Hirst, Paul. (2005) Space and Power: Politics, War and Architecture.

Bevan, Robert. (2016) The Destruction of Memory. Architecture at War. Reaktion Books.

Pullan, Wendy and Britt Baillie. (2013) Locating Urban Conflicts. Ethnicity, Nationalism and the Everyday. Routledge

مركز تحقبقات راه ، مسكن و شهرسازى خاته.

(n.d.). Retrieved April

03, 2018, from http://www.bhrc.ac.ir/

IN THE NAME OF GOD - Earthquake engineering. (n.d.) Retrieved January 3, 2018, from http://www.bing.com/ $\mathrm{Cr}$ ? IG =44584FD6EOBA426ABC57166A 1 EFB8D7F\&CID $=1$ A098A5C D7A463F32758819AD60B6219\&rd=1 \&h=9FOgLUZPwZLKA-OIC1 C1ZZB_TL8NLZPRGEMqCggBuA\&v=1 \&r=http://iisee.kenken.go.jp/ worldlist/26_Iran/Iran National Seismic Code_2007_3rd Version English.pdf\&p=DevEx,5067.1

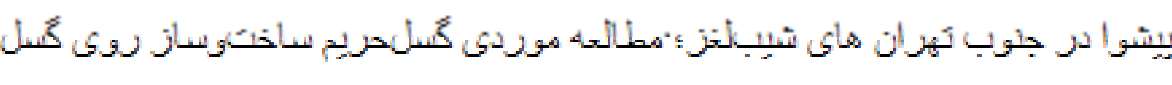

(2015, February 20). Retrieved January 03, 2018, from http://www. gsjournal.ir/article_43397.htm

Evaluation of Iranian Code No.2800 for Seismic Resistant ... (n.d.). Retrieved January 3, 2018, from https://www.bing.com/ Cr? IG=94B207B6A 11 E4384B2A23D363B043F2D\&CID=341 AE83D 735462D20AFOE3FB72FB 63CA\&rd $=1$ \&h $=2$ XhkA5VmcS3HIIDWBXM8NMaPG2IDYsiyD6vAKpmi5Tw\&v=1\&r=https://scholarsmine mst.edu/cgi/viewcontent.cgi?article=301 1 \&context=icragees$d \& p=\operatorname{DevEx}, 5068.1 .1$

A history of Persian earthquakes - Assets. (n.d.). Retrieved Janvary 3, 2018, from http://www.bing.com/cr?!G=F74655C17D734E42BA4F00C806096C8B\&CID=13EE199EEDD746C351 98B 1258ECDB6D9E\&rd=1 \& h = G 1StXYClyi5ORrH8IZQkcm6YNfAsPXgwgovth0pOGSk\&v=1\&r=http://assets.cambridge. org/97805210/21876/frontmatter/9780521021876_frontmatter. pdf\&p=DevEx,5061 
A NEW METHOD FOR EMPLOYMENT OF DETERMINISTIC ATTENUATION ... (n.d.). Retrieved January 3, 2018, from https://www. bing.com/cr? $1 \mathrm{G}=3638 \mathrm{~B} 23 \mathrm{C} 4 \mathrm{~F}$ 1944B89318DF6898329FAA\&CID=1 644A3A20B06605 C13D6A8640AA961D9\& $\mathrm{rd}=1$ \& h $=$ OgMtAQdsU8F3lyXgcYYezMJkoKibZfeBTgYwocWNh74\&v=1 \&r=https://www. researchgate.net/profile/H_Razeghi/publication/267381525_A new_method_for_employment_of_deterministic_attenuation_relationship_in_probabilistic_seismic_hazard_analysis/links/55db219508ae9d659492bcc5.pdf\&p=DevEx,5066.1

Seismotectonics and Seismic Hazard Assessment of the Sari ... (n.d.). Retrieved January 3, 2018, from http://www.bing.com/ $\mathrm{Cr}$ ?।G=F67CF64693B 64C 6BBF9DA $18 \mathrm{CD} 55 \mathrm{~F} 43 \mathrm{FF} \& \mathrm{CID}=06 \mathrm{AE}-$ BE107EC768AA0D8AB5D 67F886980\&rd= 1 \&h=FxRaxYryPnuTL6G_ SUh66n-ffu09oZGD-rGDultch41\&v=1 \&r=http://www.iitk.ac.in/ nicee/wcee/article/14_07-0136.PDF\&p=DevEx.LB.1,5514.1

Earthquake recurrence models: Topics by Science.gov. (n.d.) Retrieved January 3, 2018, from http://www.bing.com/cr?!G= COAFF3C3E25C45959D3503C17C6A4DE6\&CID=3D3F1A87614B60 E837651 14160E461 $1 \mathrm{~F} \& \mathrm{rd}=1$ \& h=cFoyhe-html\&p=DevEx,5035.1
XXOUKEllimAvE\&v=1 \&r=http://www.science.gov/topicpages/e/ fOtmFe3swt_MUBHBj3D2dWRearthquake recurrence models.

Site Effects on Amplification of Earthquke in Southwest of ... (n.d.) Retrieved January 3, 2018, from http://www.bing.com/cr? ?|G=08B6D32C8C4E4E4AA 07D47746920A8C 1 \& CID=0DD99EE36ED B69C4 1 EF 195256F74685E\&rd=1 \& h=XXFiwCf×Bz-bdqVGQUmNLehL2FIKvCPZrynbloSJw4O\&v=1 $8 \mathrm{r}=\mathrm{http}: / /$ www.iitk.ac.in/nicee/ wcee/article/14_04-02-0004.PDF\&p=DevEx,5067.1

Near-Field Earthquake Effects on Iranian Design Basis ... (n.d.). Retrieved January 3, 2018, from http://www.bing.com/cr? IG= $3210 \mathrm{D} 1$ A05D5A48D09B2E4C8CECBCFD0D\&CID $=37 \mathrm{FFBB} 86 \mathrm{CO0}$ 463073BF9B040 C 1 AB623E\& $r d=1$ \& $h=q W y 9 F 3 Y C d L 4 X 5 B W 5$ Illou KA05i811K2e3zSWMc54iCG8\&v=1 \&r=http://www.iitk.ac.in/nicee/ wcee/article/13_1398.pdf\&p=DevEx,5066.1

Dynamic Properties of Fine Grained Soils in South of ... (n.d.). Re trieved January 3, 2018, from https://www.bing.com/cr?/G=9D695990FA93412494F713F85DDA6639\&CID=3788AD6C $945463 \mathrm{E}$ F332DA6AA95FB 62D2\&rd= 1 \&h=-4HiduvAFHIEotdma0gEYShM - 
Arash_Razmkhah/publication/255667287_Dynamic_Properties of_Fine_Grained_Soils_in_South_of_Tehran/links/54de4e700cf2953c22ae68d 1/Dynamic-Properties-of-Fine-Grained-Soils-inSouth-of-Tehran.pdf\&p=DevEx,5068.1

The Management of Disasters - Waseda University. (n.d.) Retrieved October 5, 2017, from http://www.bing.com/ Cr?!|G=4D5BE6F51 4E04E8A92283537D8137AA5\&CID=32B999B 861DA63F4093E9270607562E0\&rd=1 \& h=RrpIR-Kgk_H6tXXLPD5Zf5TUiK5N_xcYwaZEOY9uql o\&v= 1 \& r =http://www.waseda.jp/ gsaps/eavi/educational_program/PDF_WS2015/Lecture 1_Reading2_Zha.pdf\&p=DevEx.LB.1,5529.1

Urban underground development an overview of historical ... (n.d.). Retrieved October 5, 2017, from http:// www.bing.com/cr? IG = 183496 A 45E7 14184 B BD 7 A 3C0A203E5D 1 \& CID $=21$ EC213343F16C5D 14532 AFB 42576D $90 \& \mathrm{rd}=1$ \& h $=$ sonfNZ2qpE39e QrljJYpltedxDyRO5 kNhTiWM $m \| I I M \& v=1 \& r=h t t p: / / i j a u p . i u s t . a c . i r / a r t i c l e-1-210-e n . p d f \& p=D e-$ VEx.LB.1,5504.1
Iran: Secrets of an Empire - Wheel \& Anchor. (n.d.). Retrieved November 5, 2017, from https://www.bing.com/cr?!G=D595CD8243C540B0853937A9FBC87155\&CID=2AD7EFC98608 6AE03CDCE40187A76BD6\&rd=1 \&h=TdzE-M3TQiMKVCLz6IUApPza4AVRuc4PqDBSIPXk5uE\&v=1 \&r=https://www.wheelandanchor.ca/events/secrets-of-an-empire-tehran-to-shi$\mathrm{raz} / \& \mathrm{p}=\operatorname{DevEx} . \mathrm{LB} .1,5069.1$ 